\title{
"تأثير التمرينات الفنية الايقاعية على بعض الذكاءات المتعددة \\ لطالبات المرحلة الاعدادية"
}

$$
\text { اعداد }
$$

مها حافظ سعد عبد العزيز سعد

موجهة تربية رياضية

$$
\text { ددرس احمد السعيد عبد الفتاح الجلمه }
$$

بكلية التربية الرياضية - جامعة كفر الثيخ
أ.د / محمد عبد السلام إبورية

استاذ ورئيس قسم علم النفس الرياضى

كلية التربية الرياضية جامعة كفر الثيخ 


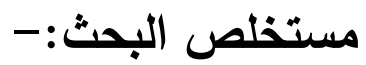

$$
\begin{aligned}
& \text { يهدف هذا البحث الى معرفةمدى تاثير التمرينات الفنية الايقاعيةعلى الذكاء الموسيقى والحركى }
\end{aligned}
$$

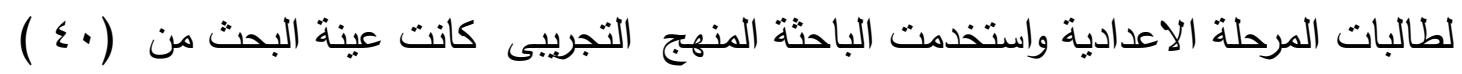

$$
\begin{aligned}
& \text { طالبة دن اجمالى( · · ()،وقد تم اختيار ( • ( ) طالبة بالطريقة العشوائية لاجراءالدراسةالاستطلاعية } \\
& \text { وفى اطار المعالجات الاحصائية المستخدمة والبيانات التى توصلت اليهالباحثة وفى ضوءالنتائج } \\
& \text { فقد اسفرت النتائج عن جود فروق ذات دلالة احصائية لصالح مجموعة البحث التجريبية لقياس } \\
& \text { البعدى بوجود تحسن فى المتغيرات قيدالبحث وكانت اهم التوصيات تطبيق برنامج التمرينات الفنية } \\
& \text { الايقاعية لتتمية الذكاء الموسيقى والحركى لطالبات المرحلة الاعدادية }
\end{aligned}
$$

\section{Abstract:- \\ Research Title: "The effect of rhythmic exercises on some multiple intelligences For middle school students"}

This research aims to know the extent of the impact of rhythmic artistic exercises on the music and movement intelligence of middle school students. The researcher used the experimental method. The research sample was from (40) female students out of a total of (100), and (20) female students were randomly chosen to conduct the exploratory study and within the framework of treatments. The statistics used and the data reached by the researcher, and in light of the results, the results have resulted in the presence of statistically significant differences in favor of the experimental research group for the dimensional measurement, in the presence of an improvement in the variables under research. Music and dynamic intelligence for middle school students 
يذكر "سامى ملحم(Y + . r) ان العصرالذى نعيش يتسم بانة عصر الانفجار المعرفى والثورة التكنولوجية ومن منطلباتة ان يكون لدى الانسان عقل يتميز بالذكاعليتعامل مع هذا الكم الهائل من المعرفة والتكنولوجيا ولقد حبا اللة الانسان هذا العقل المعجزة فى قدراتة وملكاتة و انجازاتة .

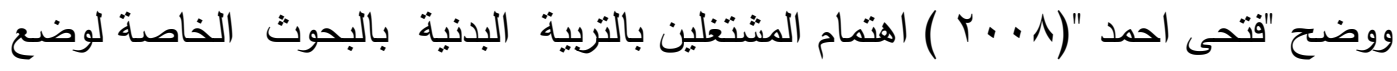
الاساليب والاسس التى تحقق اغراضها وكان من البديهى ناخذ نصيبا كبيرا من تلك البحوث باعتبارها اساس النواحى الرياضية واصلا لكل الحركات البدنية ( • ؟ r )

واعتبرت "عطيات خطاب"( T . . Y) التمرينات انها احدى انواع الانثطة الحركية التى تحتل مكانةلائقة نظرا لاهميتها الكبرى لقطاعات الثعب المختلفتسواء بالنسبة للتلميذات او العاملات او الموظفات او ربات البيوت او بالنسبة لفئات الثعب الاخرى وهى تتميز بعدم خطورتها بمقارنتها بالكثيرمن انواع الانشطة الاخرى كما انها لاتحتاج الى امكانبات وادوات خاصة او الى مكان(ملعب) معين بالاضافة الى امكانية ممارستها لاكبر عدد ممكن من الافراد فى وقت

واحد (1) (ro: (1)

وتعرفها "سامية الهجرسى "(ع . . r ) ان التمرينات الفنية الايقاعية يتعامل فيها الجسم البشرى مع القوانين الطبيعية والميكانيكية والفسلوجية والنفسية والتزبوية فى اعلى صورها وهذا يعنى ارتباط التمرينات الفنية الايقاعية بالعلوم التطبيقية المختلفة من جانب ـ اما الجانب الجوهرى الاخر فهو الترابط والتتاغم بين الابداع الحركى والابداع الموسيقى حيث تعتبر الموسيقى احد المنيرات التى تكسب دورا هاما فى فاعلية الاداء الحركى كما تعمل على نموالقدرات الابداعية والاحساسيس الذاتية داخل الفرد .( ع : : ) 
وتعرفها "زينب أحمد "( + . rم) على أنها هى "التمرينات التى لاتحتاج الى ملاعبأو مكانيات بدنية عالية المستوى وتعتمد على الحركات البدنية الطبيعية للانسان وفق الأمكانيات الفردية

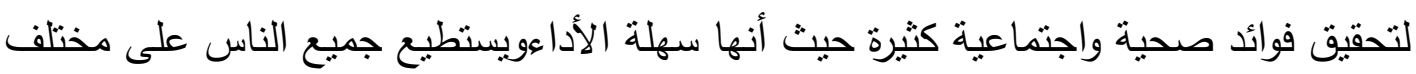

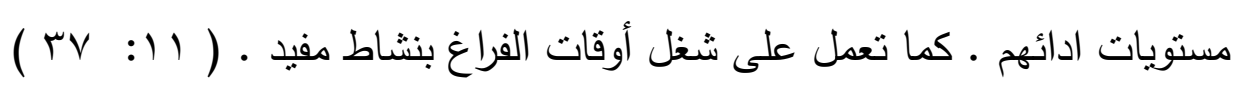
وتعرفها"سعاد الزبانى "(9 . . r) الايقاع الموسيقى بانة الثق الزمنى للموسيقى ، اى الفترة التى يستغرقها النغمة وهو عنصر اساسى فى الموسيقى • (10 :0 ) وتعرفها "نجلاء عبد الغفار محمد "( . . r ) تتظيم الاصوات الموسيقية المكونة لاى لحن الى

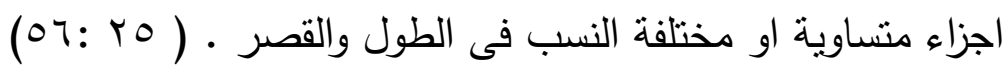
وتعرفها سعاد الزبانى "( 9 . . ) ) ان للايقاع الموسيقى رموز تقرا وتكتب بها و تسمى الاثكال الايقاعية ولكل شكل زمن محدد ويعرف بة ،ولكل شكل ايقاعى علامة تسمى سكنة نساوية فى الزمن (10 (10) - 20 (0)

ويمنلك الانسان انواع عديدة من ذكاءات متتوعة لابد من تتميتها ورعايتها لذلك وضح" جادنر " نظرية الذكاءات المتعددة والتى تؤكد ان لكل انسان ذكاء متعدد ومتتوع بدرجات متفاوتة من شخص لاخر وقدعرف "جابر عبد الحميد " (r . . الذ) الذكاءات المتعددة على انها "هى المهارات العقلية القابلة للتتمية والتى توصل اليها جاردنر والمتمثلة فى " الذكاء اللغوى - الذكاء المنطقى - الذكاء الرياضى - الذكاء الثخصى - الذكاء المكانى البصرى - الذكاء الطبيعى - الذكاء الاجتماعى - الذكاء الموسيقى - الذكاء الحركى الجسمى ". (9 : Y Y ( وبعرف "زين وهبة " (1) (1) الذكاءات المتعددة "انها مجموعة الذكاءات المتمثلة فى الذكاء اللغوى ، والرياضى، والرياضى، والدكانى ،والثخصى ،والاجتماعى ، والوجدانى،والموسيقى ، 
والحركى والتى تجعل الفرد يختلف عن غيرة من الافراد ويعمل على استغلال تلك القدرات التى

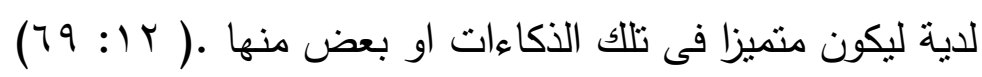
وتتمثل اهم انواع الذكاءات المتعددة فى الذكاء الموسيقى والحركى

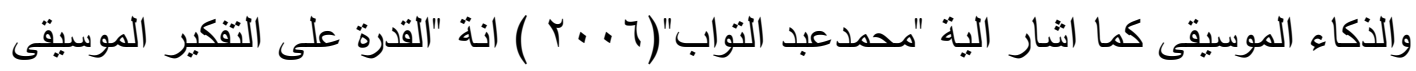
والتعرف عليها،والحساسية للاصوات والالحان والالات الموسيقية وهو القدرةعلى ادراك الصيغ

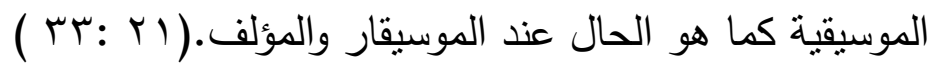
وتثثير" منال الجندى" (ج . . r) ان الذكاء الموسيقى هو أول أنماط الذكاء المشترك لدى غالبية البشر ،اذا انة من المعروف منذ نواجد الطفل فى رحم أمة و أكتمال نمو جهازة العصبى أصبح أحسى غارقا فى عالم الأصوات والايقاعات ولاتتسى ان نذكر أن تلك الايقاعات البيولوجية هى التى

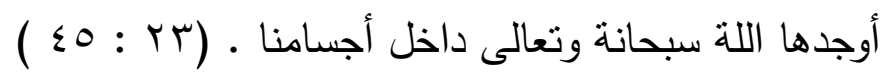

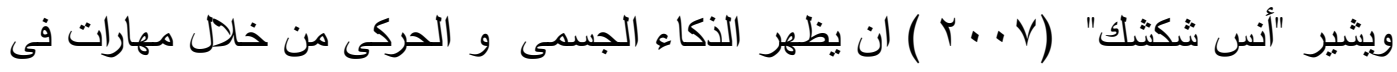
استعمال كل الجسد او اعضاء منة كاليد أو الفم لحل مشاكل معينة ، أو فى تحقيق انسياب الجمال فى الحركات المتتاسقة ،وجمال الحركات التى تؤديها الوظائف العضوية للبدن،وتتيح التحرك وممارسة الفعالية البدنية بنظام وانضباط .(0 :9 ؛ ) )

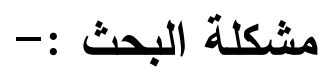

ظهرت مشكلة البحث من خلال عمل الباحثة كموجهة تربيةرياضية للمرحلة الاعدادية بادارة دسوق التعليمية ،وحيث لفت انتباة الباحثة انخفاض مستوى الذكاء الموسيقى والحركى اثثاء اداء الطالبات مهارات درس التمرينات الفنبة الايقاعية ومن خلال اطلاع الباحثةعلى الدراسات السابقة التى تتاولت تتمية الذكاءات المتعددة ( الذكاء الموسيقى والحركى ) لهذة المرحلة ،ومن هنا اقامت الباحثة بتصميم وبناء برنامج تعليمى مقترح من خلال التمرينات الفنية الايقاعية ودراسة ناثيرة على تتمية الذكاء الموسيقى والحركى لطالبات المرحلة الاعدادية 
نظرا لندرة وجود ابحاث ودراسات علمية فى هذا الاتجاة فهذة الدراسة تعتبر محاولةعلمية لتصميم برنامج لتمرينات الفنية الايقاعية ومعرفة أثزة على الذكاء الموسيقى والحركى لداء * اظهار مدى تاثير التمرينات الفنية الايقاعية على الذكاء الموسيقى * اظهار مدى تاثير التمرينات الفنية الايقاعية على الذكاء الحركى

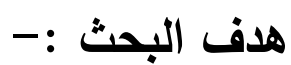

يهذف البحث الى التعرف على تأثيرالتمرينات الفنية الايقاعية على الذكاء الموسيقى والحركى

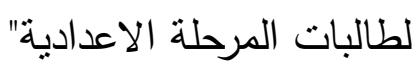

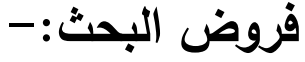

- - توجد فروق دالة احصائية بين مستوى القياس القبلى والقياس البعدى لافراد مجموعة البحث

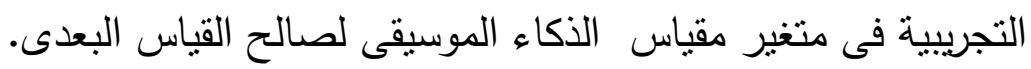
- - توجد فروق دالة احصائية بين مستوى القياس القبلى والقياس البعدى لافراد مجموعة البحث

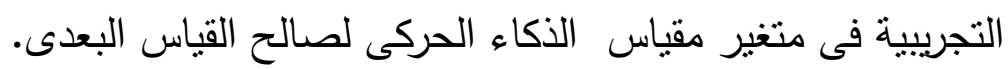
- توجد فروق دالة احصائية بين مستوى القياس القبلى والقياس البعدى لافراد المجموعة الضابطة

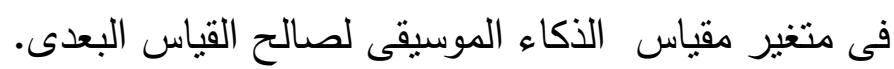
- - توجد فروق دالة احصائية بين مستوى القياس القبلى والقياس البعدى لافراد المجموعة الضابطة فى متغير مقياس الذكاء الحركى لصالح القياس البعدى.

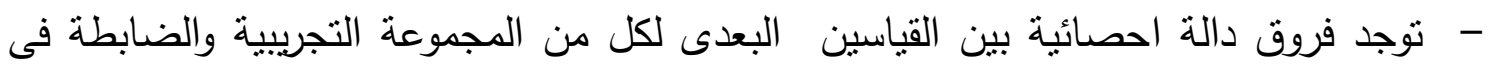
متغير الذكاء الموسيقى لصالح القياس البعدى للمجموعة التجريبية . - توجد فروق دالة احصائية بين القياسين البعدى لكل من المجموعة التجريبية والضابطة فى لئي متغير الذكاء الحركى لصالح القياس البعدى للمجموعة التجريبية. 
هى " مجموعة الاوضاع والحركات البدنية التى تستهدف تشكيل وبناء الجسم وتتمية قدراتة الحركية المختلفة للوصول للفردلاعلى مستوى من الاداء الرياضى والوظيفى وفى مجالات الحياة المختلفة

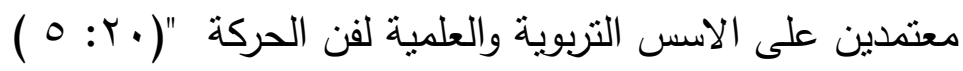

\section{Concept of multipie intellingence}

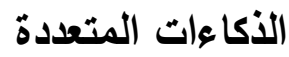

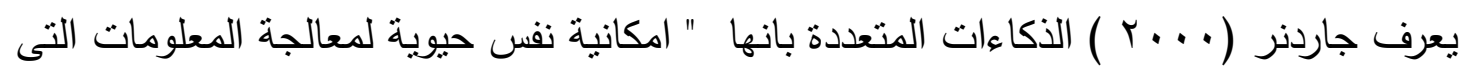
يمكن تتشيطها فى بيئة نقافية لحل المشكلات اوابتكار المنتجات التى لهاقيمة فى تقافة ما $\left(r r_{6} r \leq: r v\right)$

وتعرف الذكاءات المتعددة ايضا على انها :" مجموعة من القدرات المختلفة والمتجمعة فى التلميذ او اللاعب الواحد بدرجات متفاوتة وهذة الدرجات هى التى تحدد مدى موهبة هذا اللاعب فى

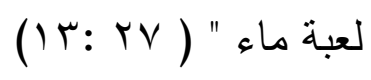

"Musical Intelligence" الأكاء الموسيقى

القدرة على ادراك الصيخ الموسيقية ( كما هو الحال عند الوسيقى المخلص المتذوق لة ) وتميزها ( كالناقدالموسيقى )وتحويلها ( كالمؤلف ) والتعبيرعنها ( كالمؤدى )ويضم الحساسية للايقاع والطبقة اواللحن والجرس او لون النغمة لقطعة موسيقية. (9 : 1) "Bodily-kinesthetic intlligenc" الأكاء الحركى الجسمى

ويعرف انة الخبرة والكفاءة فى استخدام الفرد لجسمة ككل للتعبيرعن الافكار والمشاعر ( كما هو الحال عند الممنل ، المهرج ، الرياضى ، الراقص) اليسر فى استخدام الفرد ليدية لاتتاج الاثياء او تحويلها (كما هو عند الحرفى ،المثال ، الميكانيكى ) ويضم هذا الذكاء مهارات فيزيقية محددة 
كالتازروالتوازن والمهارة والقوة والمرونة والسرعة وكذلك الاحساس بحركة الجسم ووضعة (اى الاستقبال الذاتى والاسنطاعة اللمسية ) يتضمن هذا النوع من الذكاء القدرة على استخدام المهارات الحركية فى الفنون البصرية او الادائية والالعاب الحركية والرياضة وانشطة الوسائل

$$
\text { اليدوية (9 : • (1) }
$$

اولا- منهج البحث

استخدمت الباحثة المنهج التجريبي وذللك لملاعمته لطبيعة البحث وذللك باستخدام التصميم التجريبى ذو المجموعتين ،احداهما تجريبية ،والاخرى ضابطة باستخدام القياس القبلى والبعدى للمجموعنين.

\section{ثانيا- مجتمع وعينة البحث}

يمثل مجتمع البحث طالبات الصف الثالث الاعدادى بمدرسة دسوق الاعدادية بنات بادرة دسوق

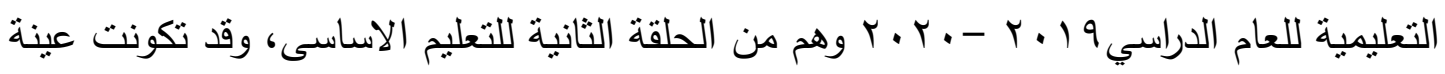
البحث من (• ع) طالبة من إجمالي ( · . 1 ) طالبة، بالاضافةالى اختبار (·r ) طالبة بالطريقة العشوائية من مجتمع البحث وخارج العينة الاساسية لإجراء الدراسة الاسنطلاعية. وتم تقسيمهر

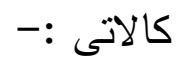
1- المجموعة الضابطة: وقد شملت (·r) طالبة بطبق عليهم البرنامج التقليدى. Y- المجموعة التجريبية :وقد شملت (·r) طالبة بطبق عليهم البرنامج التعليمى المقترح. r- عينة الدراسة اللاستطلاعية: وقد شملت( • (ب)طالبة من مجتمع البحث الاصلى وخارج

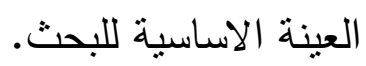




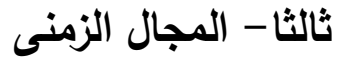

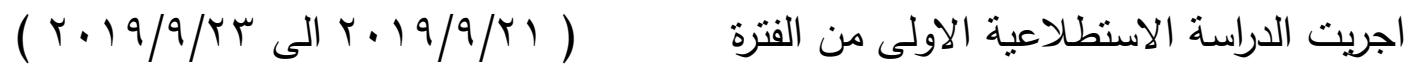

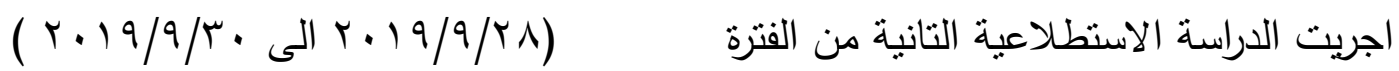

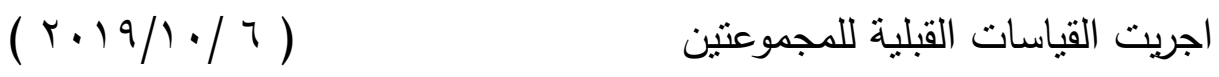

$$
\begin{aligned}
& \text { تم تطبيق البرنامج من }
\end{aligned}
$$

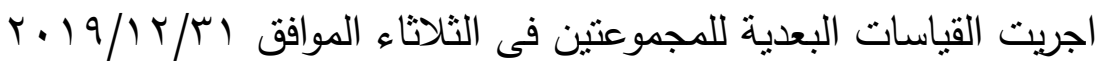

اعداد مواد المعالجة التجريبية:

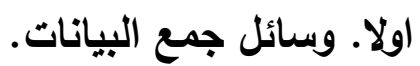

قامت الباحثة بتحديد البيانات المستخدمة فى البحث الى ما يلى: 1- ادوات الدلالة علي معدلات النمو وقد تمتلت في القياسات التالية: أ- العر الزمني: بالرجوع إلي تاريخ الميلاد " لاقرب سنه "

ب- الطول: بواسطة استخدام جهاز الرستاميتر " لاقرب سنتيمتر " ج- الوزن: بواسطة الميزان الطبي "لاقرب كيلو جرام. r- الاختبارات المستخدمة في البحث:

أ : : اختبار القرات العقلية للأكاء للصغار والكبار "اعداد /سامية الانصارى .مرفق(ץ ) استخدمت الباحثة اختبار الذكاء المصور التى قامت بتصميمة د/سامية الانصارى ويتكون الاختبار من (·) (7ؤال متدرج فى الصعوبة مدتة (0؛ )دقيقة فهذا الاختبار يحتوى على عدد من الاسئلة الذهنية والاثكال تقيس قدرة المتعلمين على التفكير. 
ب : مقياس الذكاء الموسيقى "اعداد / احمد السعيد الجلمة " مرفق (r)

ج : مقياس الذكاء الحركى "اعداد / احمد السعيد الجلمة " مرفق (ع).

استخدمت الباحثة مقياس الذكاءات المتعددة قيد البحث من تصميم /احمد السعيد عبد الفتاح الجلمة واستخدمت منة نمط الذكاء الموسيقى والحركى • (1 :

وقد قامت الباحثة بعمل المعاملات الاحصائية للاختبارات سالفة الذكر (معاملات الصدق ، الثبات

ثانيا. البرنامج التعليمى المقترح باستخدام مهارات التمرينات الفنية الايقاعية.

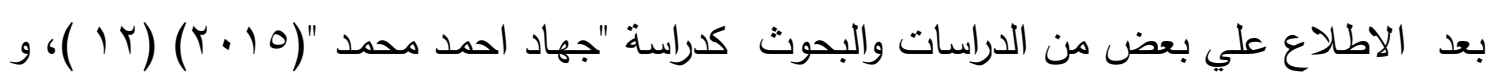

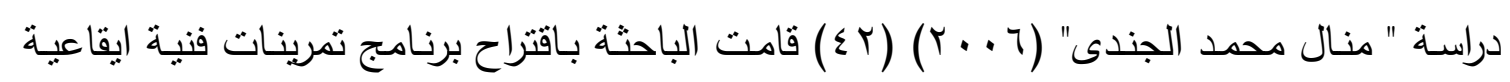

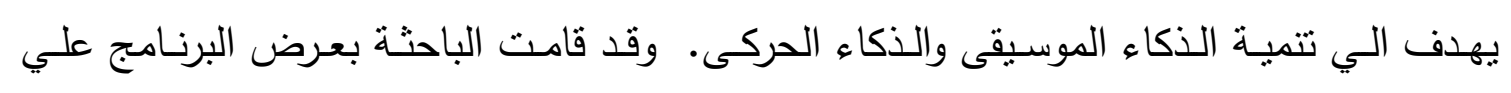

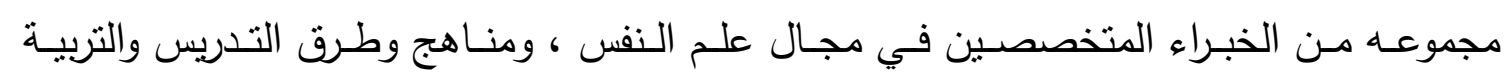

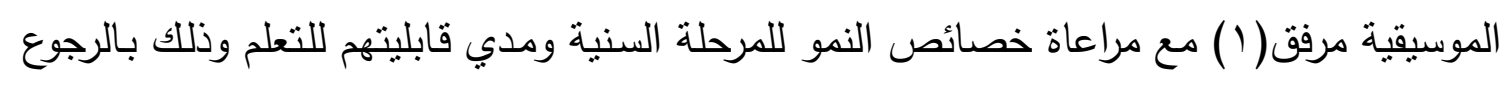

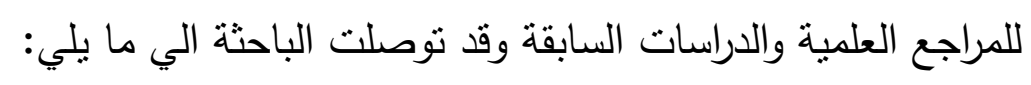

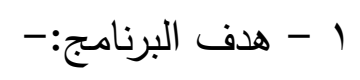

- تـاثير التمرينـات الفنبـة الايقاعيـة على تتميـة الذكاء الموسبقى و الحركى لطالبـات المرحلـة

$$
\text { r- اغراض البرنامج:- }
$$

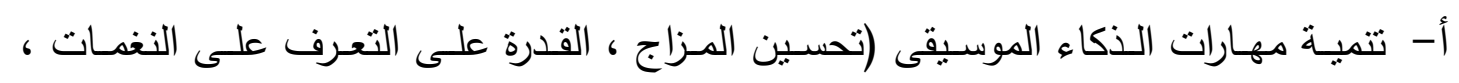

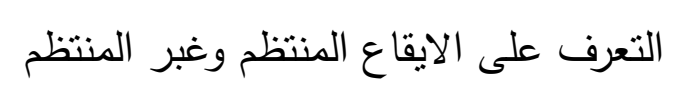

ب-تتمية مهارات الذكاء الحركى(توافق، مرونة، رشاقة، سرعة استجابة )

ت-اكتساب الطالبات مهارات حركيه ايقاعية تساعدها علي اكتساب مهارات اللياقة البدنية.

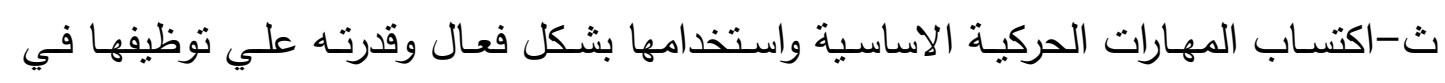
حياتها اليومية .

ج- استمتاع الطالبات بالتمرينات الفنية الايقاعية وإثباع حاجاتهم من خلال النشاط الحركي

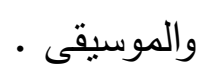


تمت مراعاة مجموعة من الاسس العلمية عند تصميم البرنامج وهى كالتالى. أ- مراعاة الهحف من البرنامج بما يتتاسب مع محتوى مقرر التدريس لطلبة المرحلة/لاعدادية.

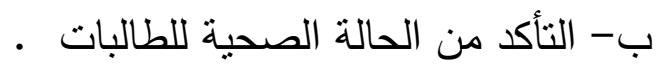
ت- مراعاه خصائص النمو لهذه المرحلة . ث-يناسب محتوي البرنامج مع أهدافه . ج- مناسبه الأنشطة الحركية لقدرات الطالبات واستعدادهم • ح- مناسبه الأنشطة الحركية والموسيقية للإمكانات المادية والبشرية المتوفرة . خ- ربط النشاط الحركي بالايقاع الموسيقى.

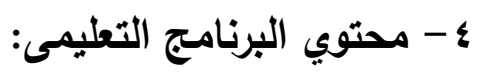

تم وضع البرنامج التعليمى ليتمانشى مع رغبات واحتياجات الطالبات في هذه المرحلة العمرية لتتمية الذكاء الموسيقى والحركى عن طريق مهارات التمرينات الفنية الايقاعية لطالبات المرحلة الاعدادية

\section{ه- ضبط المحتوي:}

في ضوء ما سبق قامت الباحثة ببنـاء محتوي البرنامج، وتم وضعه في استمارة استطلاع رأي

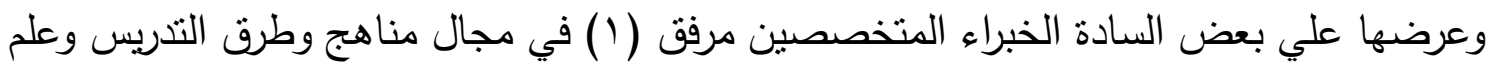
النفس الرياضي ببعض كليات التربية الرياضية ومجال التربية الموسيقية لإبداء الراي فيه بهدف فئف

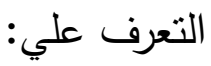
- 
- - - الامكانيات اللازمة لتنفيذ البرنامج.

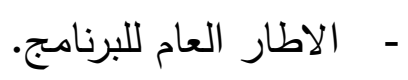
צ- اساليب التدريس المستخدمة في تنفيذ البرنامجج.

تم تحديد اسـاليب العرض التوضيحى باستخدام التمرينـات الفنيـة الايقاعيـة وذلك لتتميـة الذكاء

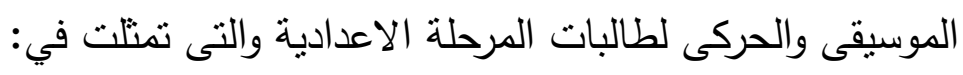
- - الاسلوب التقليدى (الثرح والتتفيذ) للمجموعة الضابطة. - ادخال الادوات والمقاطع الموسيقية والادوات الجديدة في التعلم والتعلم في مجموعات ـ ـ

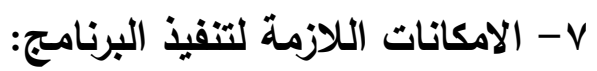

راعت الباحثة على ان تكون اساليب ووسائل تتفيذ البرنامج التعليمى تكون مناسبة لتتفيذة ومراعية للحالة السنية وتمثلت هذه الوسائل والامكانات فيما يلى : لئل : - م - اختبار القدرات العقلية (الذكاء المصور ) -

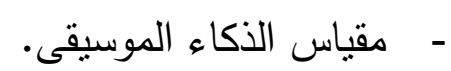

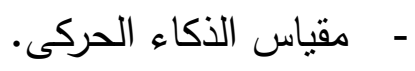
-

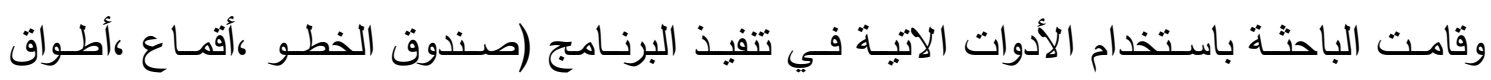

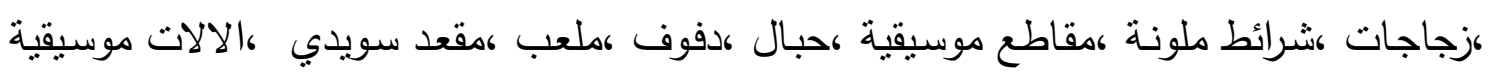
مختلفة ، سماعات ). 1- الاطار الزمني لتنفيذ البرنامج:

يتكون البرنامج من من خلال (Y ( ) درس موزعة علي (1) درس اسبوعيا لمدة ب شهور على مدار

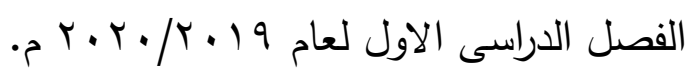
علي أن يكون الثكل النهائي للاروس علي النحو الثالي : الجزء التمهيدي (· (دقائق ) ويضم

اعمال ادارية (0 دقائق ) والاحماء (0 دقائق ) والاعداد البدنى (0r دقيقة ) 


$$
\text { • الجزء الرئيسي(• •دققيقة) ويضم }
$$

النشاط التعليمى (0 بدقيقة) والنشاط التطبيقى (0 دقيقة )

$$
\text { الجزء الختامي ( - ( د دقائق ) }
$$

وبذلك يكون الزمن المخصص لوحدة (.9 دقيقة )

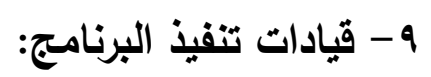

قام الباحث بتنفيذ البرنامج التعليمى المقترح

• 1 - اساليب التقويم المستخدمة في البرنامج التطليمى المقترح .

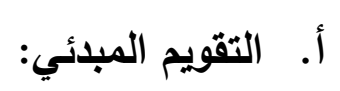

يتم قبل البدء في تتفيذ البرنامج ويعطي معلومة مهمة علي المحتوي ويتم ذلك من خلال التطبيق

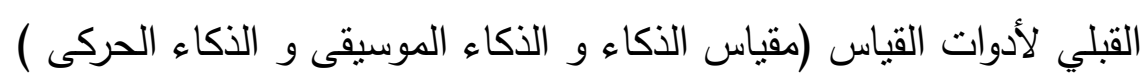

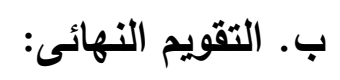

وهو القياس البعدي لأفراد العينة بعد تطبيق البرنامج لمعرفه ما حققه البرنامج من نتائج وما تم من تتمية الذكاء الموسيقى والحركى.

الاراسات الاستطلاعية:- - -

اولا: الاراسة الاستطلاعية الاولى :

قامت الباحثة باجراء الدراسة الاستطلاعية الاولى لاجراء المعاملات العلمية (صدق

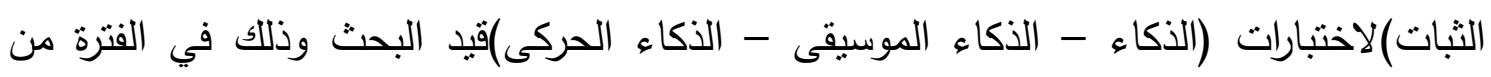

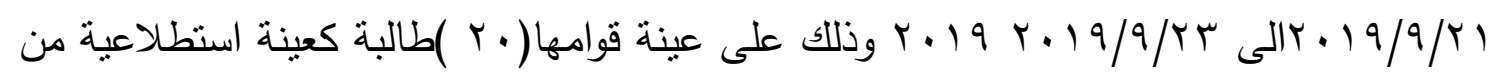
طالبات الصف الثالث الاعدادى بالمدرسة وهى من نفس مجتمع البحث ومن خارج العينة الاساسية وذلك بهدف تقنين جميع الوسائل والاختبارات المستخدمة في البحث. 


\begin{abstract}
- - التاكد من صلاحية الوسائل والادوات المستخدمة في البحث.

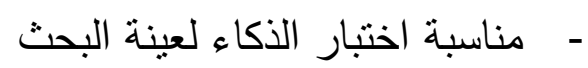

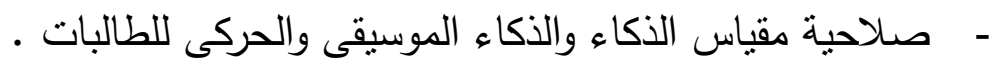
- - مناسبة زمن الحصة لتنفيذ برنامج التمرينات الفنية الايقاعية.
\end{abstract}

\title{
ثانيا: الدراسة الاستطلاعية التانية :-
}

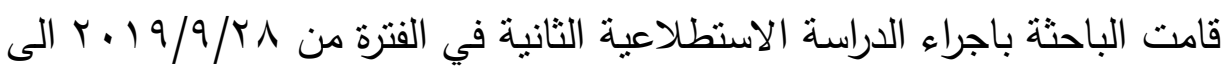

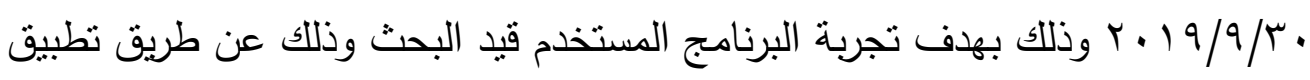

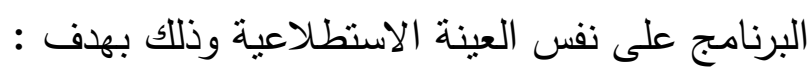

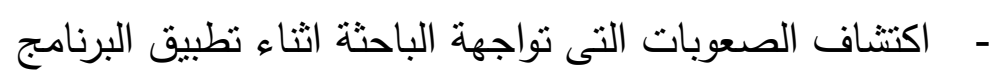
- - التاكد من صلاحية المكان ومناسبتة لتطبيق البحث - التاكد من مناسبة الزمن المخصص للحصة لنطبيق الاساليب التعليمية الخاصة بالبحث

\section{الاراسة الاساسية للبحث:}

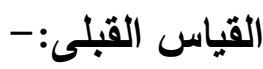
قامت الباحثة باجراء القياس القبلى للمجموعتين التجريبية والضابطة يوم الاحد

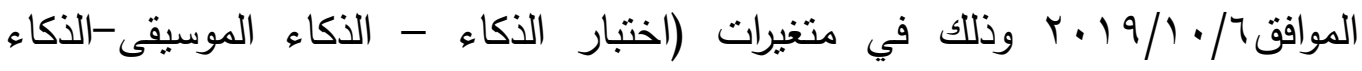
الحركى )وذلك على عينة البحث الاساسية المجموعتين التجريبية والضابطة بهدف التجانس بين افراد عينة البحث. تجانس وتكافؤ عينة البحث في المتغيرات الاساسية قيد البحث اعتدالية نوزيع البيانات وضبط المتغيرات : للتاكد من وقوع افراد عينة البحث تحت المنحنى الاعتدالى .قامت الباحثيطة بات باجراء التجانس بين افراد عينة البحث في بعض المتغيرات المختارة معدلات النمو (السن),والقدرات العقلية (الذكاء), ,والذكاء الموسيقى والحركى. لئه 
للتأكد من خلو البحث من عيوب التوزيعات غير الاعتدالية تم حساب المنوسط الحسابي

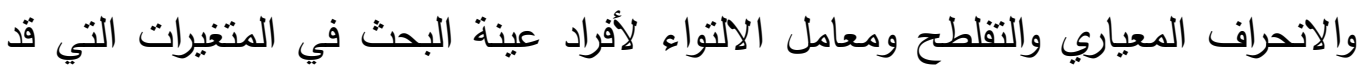

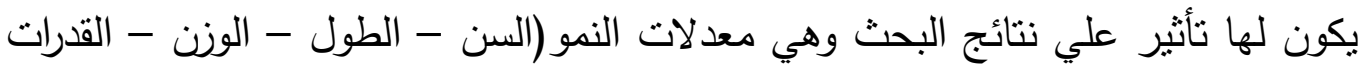
العقلية)، مقياس الذكاء الموسيقى ،ومقياس الذكاء الحركى.

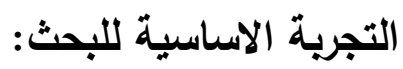

تم تتفيذ الدراسة الاساسية علي العينة التجريبية عقب القياس القبلي وذلك في الفترة من الاتتين

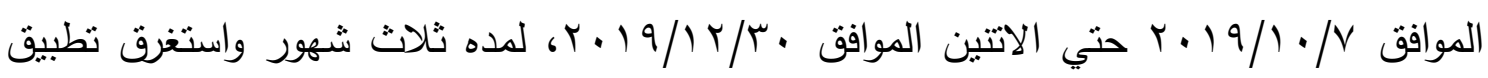

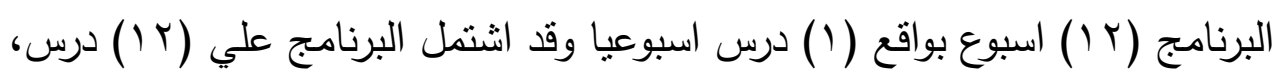

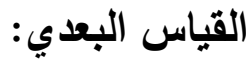

تم اجراء القياس البعدي علي مجموعتى البحث التجريبية والضابطة بعد الانتهاء من

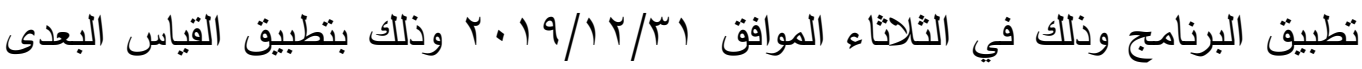
لكل من الذكاء الموسيقى و الحركى لطالبات المرحلة الاعدادية.

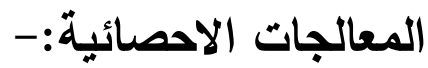

استخدمت الباحثة المعالجات الاحصائية النالية:

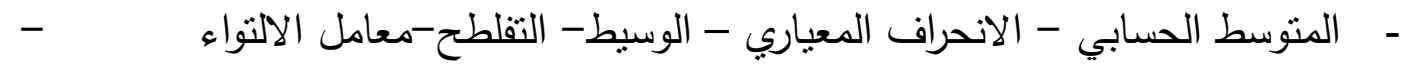

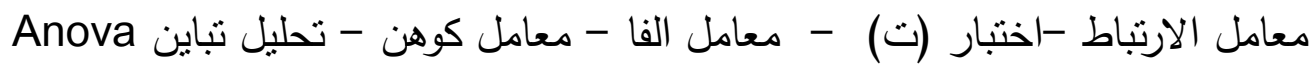

تم عرض نتائج البحث وقد اسفرت ان التمرينات الفنيـة الايقاعيبـة لها تاثثر ايجابى على تتميـة الذكاء الموسيقى والحركى لطالبات المرحلة الاعدادية. 


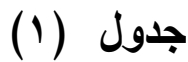

\section{دلالة الفروق بين القياس القبلي والبعدى لدى مجموعة البحث التجريبية فى عبارات مقياس الذكاء الحركى لئى لائ}

\begin{tabular}{|c|c|c|c|c|c|c|c|c|c|}
\hline \multirow{2}{*}{ ن التحسب معدل } & \multirow{2}{*}{ قيمة ت } & \multirow{2}{*}{ المعباري } & \multirow{2}{*}{ فروق المتوسطا } & \multicolumn{2}{|c|}{ القياس البعدى } & \multicolumn{2}{|c|}{ القياس القبلي } & \multirow{2}{*}{ العبارات } & \multirow{2}{*}{ b } \\
\hline & & & & $\varepsilon^{ \pm}$ & س س & $\varepsilon^{ \pm}$ & س س & & \\
\hline משr.A. & $1 . .1 \mathrm{VV}$ & $.1 Y \wedge$ & $1 . r$. & $.01 r$ & r.o.. & $\cdot . \leqslant 1$ & $1 . r \ldots$ & 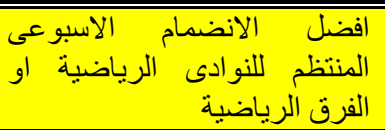 & 1 \\
\hline זrז.זה & $1.17 r$ & . & 1.10. & $\cdot . \leqslant \varepsilon \leqslant$ & r.vo. & $.01 T$ & $1.0 \ldots$ & حركاتهم وسلوكياتهم الاخرين فى القل & r \\
\hline $1 \cdot V . \varepsilon \cdot V$ & $9 . \leqslant \leqslant \wedge$ & $.10 r$ & $1 . \leqslant 0$. & $\cdot \leqslant 1$ & Ү.^.. & $\cdot \leqslant \wedge 9$ & 1. & باستمر ار مع الاخرين التحدى و المنافسة & r \\
\hline $97.00 \%$ & $11.1 \leqslant r$ & .147 & $1 . \varepsilon$ & דצדי. & r. 10. & תו & $1 . \leqslant 0$. & او مدرب ان اصبح مهندس معمارى رياضى . أعب & $\varepsilon$ \\
\hline $149.17 \mathrm{~V}$ & $1 T .011$ & $.11 \leq$ & 1.00 & $\cdot . \leqslant \varepsilon \leqslant$ & r.vo. & $\because \leqslant 1$ & $1 . r \ldots$ & كثير من الاعمال اليومية البية الثاقة فى & 0 \\
\hline $1 \ldots \cdots$ & $1.1 \cdot r$ & $.17 V$ & 1.0. & 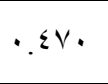 & r.v.. & $\cdot \leqslant \wedge q$ & $1 . r 0$. & الكلبة. دراسة المو اد العلمية فى & 7 \\
\hline IrA.... & 11.971 & $.1 T \leq$ & $1.7 \ldots$ & צדיז. & r. 10. & $\cdot . \leqslant \leq \leqslant$ & 1.50. & بعض الالعاب الرياضية والجرى وممارسة . المضل & V \\
\hline $1 \% q .1 \%$. & IE.TM & $.11 \mathrm{r}$ & $1.7 \ldots$ & $\cdot . \leqslant \varepsilon \leqslant$ & r.vo. & תו & 1.10 & المثبرة. ممارسة الالعاب الجديدة & $\wedge$ \\
\hline VA. I ro & $V . Y \wedge I$ &.$I V T$ & $1 . r 0$. & $\cdot \leqslant 1$ & r.10. & $.0 . r$ & $1.7 \ldots$ & 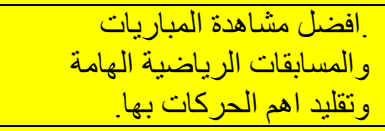 & 9 \\
\hline سזr. • ו & $\wedge . \wedge 0$. & $\cdot 1 \leqslant V$ & $1 . r \ldots$ & $.01 \pi$ & r.o.. & $\cdot \varepsilon 1$ & $1 . r \ldots$ & 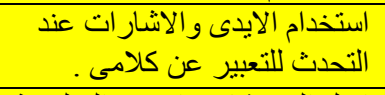 & 1 . \\
\hline $1 \leq V . \wedge Y 7$ & 17.18 & .1 .0 & $1 . \vee \ldots$ & תדיז & r. 10. & & 1.10 & والميل الى مشـاهدة الافلام البوليسية & 11 \\
\hline 111.111 & $I T . V V$ & .110 & $1.0 \ldots$ & צדית. & r.10. & $\because \leqslant \wedge 9$ & $1 . r 0$ & 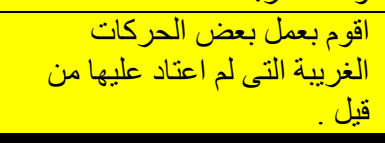 & ir \\
\hline צזr. • & $1 \leq .907$ & $1.1 T V$ & 17.10 & $r . \leqslant \wedge 1$ & (ז.... & 1.911 & 17.10 & المجموع & \\
\hline
\end{tabular}

قيمة ت الجدولية عند مستوى معنوية ه . . =9 Y Y 1.

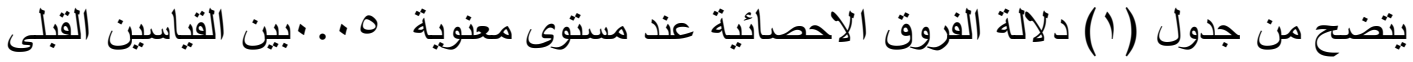
والبعدى لدى مجموعة البحث التجريبة فى عبارات مقياس الذكاء الحركى وقد تراوحت قيمة ت

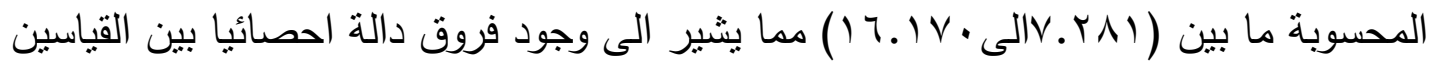

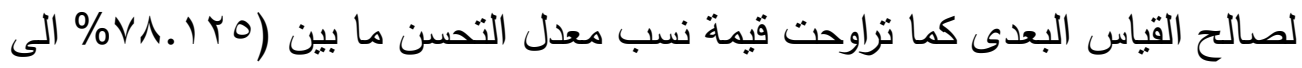
$(\%) \leqslant V . \wedge r 4$ 


\section{جدول (r) (r)}

\section{دلالة الفروق بين القياس القبلي والبعدى لاى مجموعة

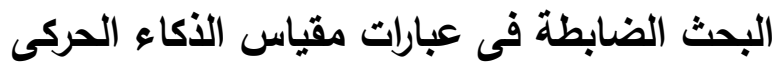

$r \cdot=\dot{0}$

\begin{tabular}{|c|c|c|c|c|c|c|c|c|c|}
\hline \multirow{2}{*}{ نسب معدل } & \multirow[b]{2}{*}{ قيمة ت } & \multirow{2}{*}{ الخطأ } & \multirow{2}{*}{ فروق } & \multicolumn{2}{|c|}{ القياس البعدى } & \multicolumn{2}{|c|}{ القياس القبلي } & \multirow[t]{2}{*}{ العبارات } & \multirow[t]{2}{*}{ م } \\
\hline & & & & $\varepsilon^{ \pm}$ & س س & $\varepsilon \pm$ & س س & & \\
\hline rI.Vrq & r.rוT & ror. &. ro. & r. & $1 . \varepsilon \ldots$ & דצז. & 1.10. & اللنوادى الانضمام الاسبوعى المنتظم الفية الفرق & 1 \\
\hline$r \ldots$. & r.VIr & .101 & . . . . & .0911 & I.^.. & .011 & $1.0 \ldots$ & وسلوكياتهم اقلا الاخرين فى حركاتهم & $r$ \\
\hline 11.111 & 1.01 & $.1 \wedge r$ & .10 &.$\neg \wedge \wedge$ & $1.0 \ldots$ &..$\leqslant \wedge q$ & . סא. & 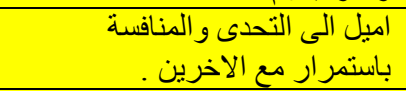 & r \\
\hline $1.0 \mathrm{VI}$ & 1.178 & .179 & .10 &. $.7 \vee 1$ & 1.9. &..$\leq \leq \leq$ & I.vo. & مدرب اتمنى ان اصبح مهندس معمارى او رياضى . لاوب & $\varepsilon$ \\
\hline |V.rq & r.rqq &. $.1 T V$ & . r. &.$\leqslant \wedge q$ & . סז.1. & דצץ. & 1.10. & كثير من الاعمال اليومال البدنية الثاقة فئى & 0 \\
\hline 11.111 & 1.110 & $.017 V$ & .10 &.$\neg \wedge \wedge$ & $1.0 \ldots$ &..$\leqslant \wedge 9$ & ס. 1. & الكلبة. دراسة المواد العلمية فى & 7 \\
\hline $17.77 \mathrm{~V}$ & I.vov & $.10 \leqslant$ &.$r$. &.$\neg \wedge \wedge$ & $1.2 \ldots$ &.$\leqslant 1$ & I.r. & 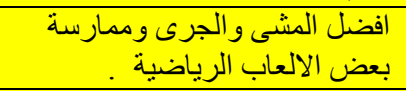 & V \\
\hline |V.rq & $1 . \wedge \vee 1$ & $.1 \leq V$ & $. r .$. & .7 .0 & . סז.1. & דצז. & 1.10. & المثبرة ممارسة الالعاب الجديدة & $\wedge$ \\
\hline$\wedge .0 \vee 1$ & 1. ro & $.1 \wedge 7$ & .10 &.$\neg \wedge 7$ & $1.9 \ldots$ &..$\leq \leq \leq$ & 1.80. & و المسابقات الرياضبة مشاهدة المباريات الهامة وتقليد & 9 \\
\hline 1.797 & $1 . r \wedge 9$ &. $.11 \mathrm{r}$ & $.1 \ldots$ & .00 & 1.ro. & דצץ.. & 1.10 & 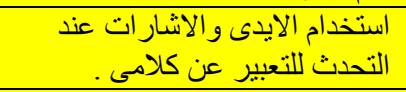 & 1. \\
\hline rז... & rצrr & $.1 \leq 7$ &. ro. &.$\neg \wedge 7$ & $1 . \leqslant 0$. &.$\leqslant 1$. & I.r... & والميل الى مشاهدة الافلام البوليسية & 11 \\
\hline $10 . r$ مo & $1 . \wedge 1 \wedge$ & .10 & $\cdot r \cdot$ &.$\leqslant \wedge q$ & $1.0 \ldots$ & $\because \varepsilon V$ & I. . . & التوم بعمل بعض الحم اعتاد عليها من فيل الغريبة & Ir \\
\hline IE.TVO & r..10 &.$\vee \wedge \neg$ & ק.r. & Y.EI & |ᄉ.r.. & rצחי & $17 \ldots$ & المجموع & \\
\hline
\end{tabular}

قيمة ت الجدولية عند مستوى معنوية 0 . . = = يتضـح من جدول (Y) دلالة الفروق الاحصـائية عند مستوى معنوية ه ـ. •بين القياسين القبلى والبعدى لدى مجموعة البحث الضـابطة فى عبارات مقياس الذكاء الحركى وقد تراوحت قيمة ت

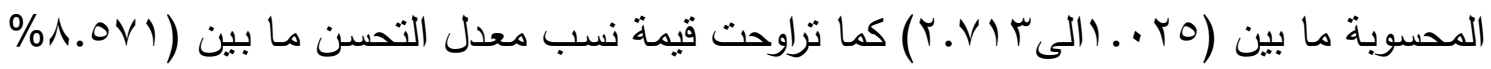

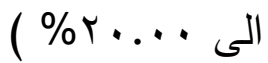




\section{جلول (r)}

دلالة الفروق بين القياسات البعدية لاى مجموعتى

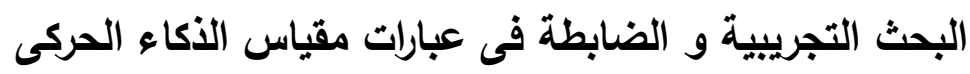

$r \cdot=r \dot{ }=1 \dot{0}$

\begin{tabular}{|c|c|c|c|c|c|c|c|c|}
\hline \multirow{2}{*}{ فرق نسب } & \multirow[b]{2}{*}{ قيمة ت } & \multirow{2}{*}{ فروق } & \multicolumn{2}{|c|}{ المجموعة الضابطة } & \multicolumn{2}{|c|}{ المجموعة التجريبية } & \multirow[t]{2}{*}{ العبارات } & \multirow[t]{2}{*}{ p } \\
\hline & & & $\varepsilon^{ \pm}$ & س & $\varepsilon \pm$ & س & & \\
\hline $17.09 \leq$ & $7.7 \vee 7$ & $1.1 \ldots$ & .0 .1 & $1 . \varepsilon \ldots$ & $.01 T$ & r.o.. & 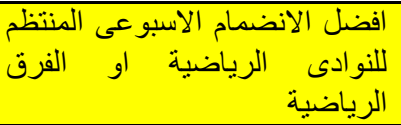 & 1 \\
\hline אחז.זר & $0.00 \mathrm{~V}$ & .90 & .091 & I.^.. & $\cdot . \leqslant \leqslant \leqslant$ & r.Vo. & وسلوكياتهم اقلد الاخرين فى حركاتهم & r \\
\hline 97.197 & $V . \cdot V T$ & I. & $.7 \wedge \wedge$ & $1.0 \ldots$ & 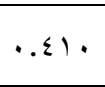 & r.^.. & باستيل الى التحدى و المنافسة الاخرين . & r \\
\hline$\wedge \vee .9 \wedge$. & $0 . \varepsilon \mid 1$ & .90 &. $.7 \vee 1$ & $1.9 \ldots$ & דודז. & r.AO. & 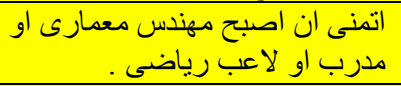 & $\varepsilon$ \\
\hline $111.2 \vee 0$ & מדזים & $1 . \varepsilon \ldots$ & $\because \leqslant \wedge 9$ & 1. & $\because \leq \leq \leq$ & r.vo. & كثير من الاعمال اليومية البية الثاقة فى & 0 \\
\hline$\wedge \wedge . \wedge \wedge q$ & T. rVo & I.r. & $.7 \wedge \wedge$ & $1.0 \ldots$ & $\because \Sigma V$ & r.V. & الحلبة دراسة المو اد العلمية فى & 7 \\
\hline 11111 & A. 1.7 & $1 . \leqslant 0$. &. $.7 \wedge \wedge$ & $1 . \varepsilon \ldots$ & דודז. & r.Ao. & بعض الالعل المشى و الجرى وممارسة & V \\
\hline IrI.VTq & A.ITr & $1 . \varepsilon \ldots$ & .7 .0 & 1. &..$\leq \leqslant \leq$ & r.vo. & المثبرة ممارسة الالعاب الجديدة & $\wedge$ \\
\hline $79.00 \leqslant$ & $0.1 V \wedge$ & .90 &. $.7 \wedge 7$ & $1.9 \ldots$ &.$\varepsilon 1$ & r.^o. & و المضابقات مشاهدة المباريات الحباضية الهامة وتقلبد & 9 \\
\hline 99.71 & $V . r \leq \varepsilon$ & $1 . r 0$. & .00 & 1. ro. & $.01 \%$ & r.o. & 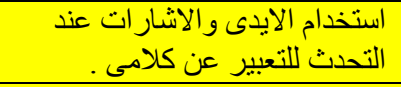 & 1 . \\
\hline $1 \times 7.994$ & $V . \wedge \leq \varepsilon$ & $1 . \varepsilon \ldots$ & $.7 \wedge 7$ & $1 . \leqslant 0$. & 1דו & r.Ao. & والميل الى مشاطدة الافلام البوليسية & 11 \\
\hline $90 . V Y 7$ & $9.7 r 7$ & 1. & $\because \leqslant \wedge 9$ & $1.0 \ldots$ & דוצח. & r.^o. & 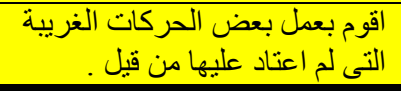 & it \\
\hline 19.909 & $11.01 \mathrm{~V}$ & $1 \leq . V \cdot$ & r.sIr & १^.ґ.. & $r . \Sigma \wedge l$ & & المجموع & \\
\hline
\end{tabular}

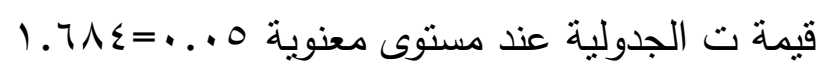

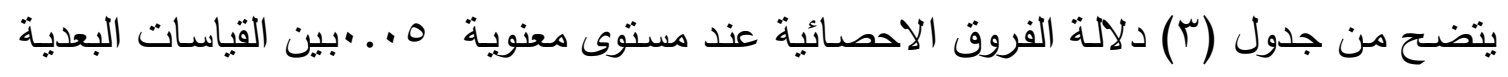

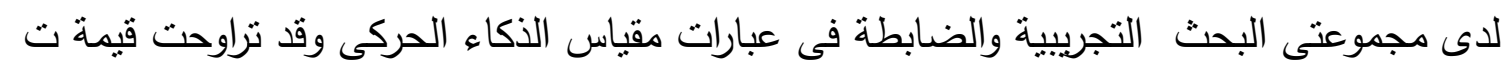

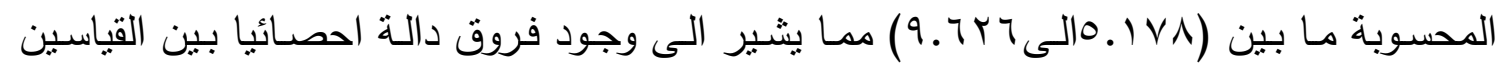

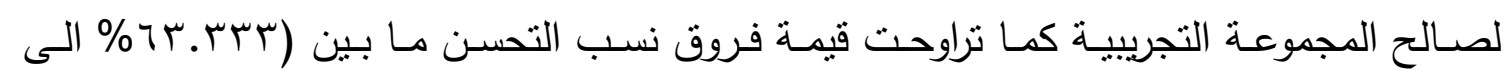




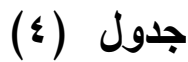

دلالة الفروق بين القياس القبلي والبعدى لاى مجموعة

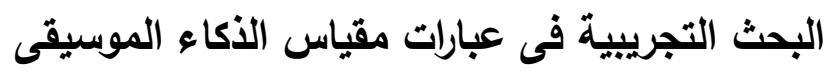

\begin{tabular}{|c|c|c|c|c|c|c|c|c|c|}
\hline \multirow{2}{*}{ نسب معدل } & \multirow[b]{2}{*}{ ق ق قيمة ت } & \multirow{2}{*}{ الخطأ } & \multirow{2}{*}{ فروق المتوسطا } & \multicolumn{2}{|c|}{ القياس البعدى } & \multicolumn{2}{|c|}{ القياس القبلي } & \multirow{2}{*}{ العبارات } & \multirow[t]{2}{*}{ p } \\
\hline & & & & $\varepsilon^{ \pm}$ & س س & $\varepsilon^{ \pm}$ & س س & & \\
\hline $11 \mathrm{V.rq1}$ & l.rNr &. $.1 T 1$ & $1 . r 0$. & $.01 r$ & r.o.. & תוצד & 1.10 & 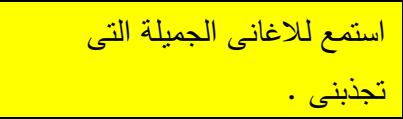 & 1 \\
\hline 19.700 & $1 . .1 \mathrm{VV}$ & $.1 r \wedge$ & $1 . r \ldots$ &..$\leq \leq \leq$ & r.vo. & .01 & $1 . \leqslant 0$ & اشعر بايقاعات الموسيقى. & r \\
\hline $1 \cdot v . \varepsilon \cdot v$ & $9 . \leqslant \leqslant \wedge$ & $.10 r$ & $1 . \leqslant 0$. & .. & r.^.. & $\because \leqslant \wedge 9$ & $1 . r 0$. & اجرك اليد او القدم او ایى من الجسم عند سماع الموسيقى. & $r$ \\
\hline VA. IYO & A.vor & $. .1 \leq r$ & $1 . r o$. & צדים & r.AO. & $.0 . r$ & $1.7 \ldots$ & 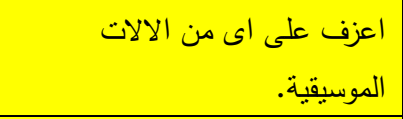 & $\varepsilon$ \\
\hline $1+9.1 \%$. & IE.rT4 & $.11 r$ & $1.7 \ldots$ & $\therefore \leq \leqslant \leq$ & r.Vo. & צוצד & 1.10 & دون قدن بعض الاغانى التى افضلها & 。 \\
\hline $1.8 .79 r$ & $\Lambda . r \cdot \varepsilon$ & .179 & $1 . \varepsilon \cdots$ & $\therefore \leqslant \vee$ & r.V.. & $\cdot . \leqslant \vee$ & I.r... & 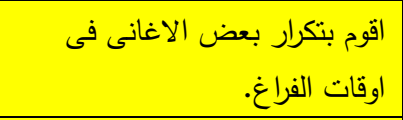 & 7 \\
\hline $1 \leq V . \wedge T_{T}$ & $17.1 \mathrm{~V}$ & .1 .0 & $1 . v \ldots$ & - & r.Ao. & - & 1.10 & اذكر وانا اسمع الموسيقى & v \\
\hline 1rq.1T. & IE.rTy &. $.11 r$ & $1.7 \ldots$ & $\therefore \leq \leqslant \leq$ & r.Vo. & צוצ & 1.10 & 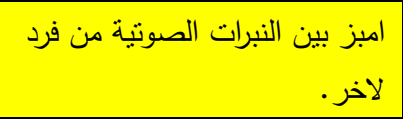 & $\wedge$ \\
\hline $94.1 \cdot r$ & $1.1 \cdot r$ & .178 & $1 . r 0$. & .. & r.A.. & .01 & $1 . \leqslant 0$. & والغنارك بالحفلات الموسيقية فى المناسبات والحفلات. & 9 \\
\hline $\mid 1 v . r q 1$ & 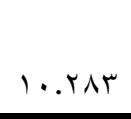 &.$|r|$ & $1 . r 0$. & $.01 r$ & Y.०.. & צדיט. & 1.10 & 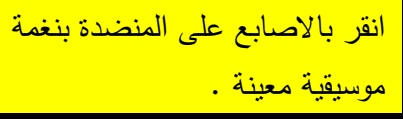 & 1. \\
\hline $111 . r \leq$. & rl. $\leqslant$ r. & $.7 V$ & Is.ro. & r.rTA & rV.ro. & t.rAT & 1 1 . . . . & المجموع & \\
\hline
\end{tabular}

$$
\text { قيمة ت الجدولية عند مستوى معنوية ه . . = }
$$

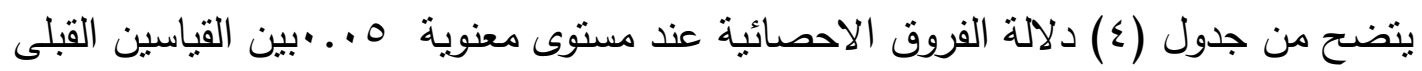
والبعدى لدى مجموعة البحث التجريبة فى عبارات مقياس الذكاء الموسيقى وقد تراوحت قيمة ت

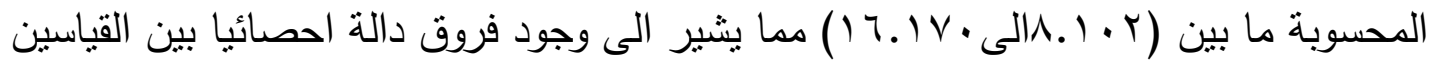

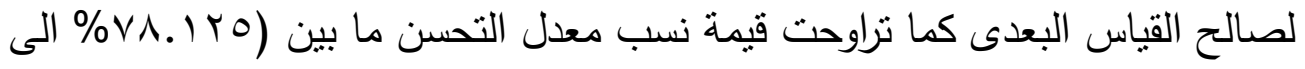




\section{جدول (0)}

دلالة الفروق بين القياس القبلي والبعدى لدى مجموعة

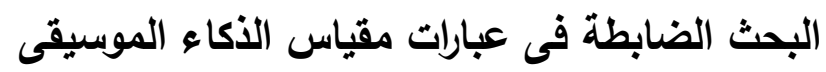

\begin{tabular}{|c|c|c|c|c|c|c|c|c|c|}
\hline \multirow{2}{*}{ نسب معدل } & \multirow[b]{2}{*}{ قيمة ث } & \multirow{2}{*}{ للمتوسطأ } & \multirow{2}{*}{ فروق المتوبطا } & \multicolumn{2}{|c|}{ القياس البعدى } & \multicolumn{2}{|c|}{ القياس القبلي } & \multirow[t]{2}{*}{ العبارات } & \multirow[t]{2}{*}{ r } \\
\hline & & & & $\varepsilon \pm$ & 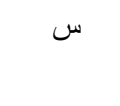 & $\varepsilon \pm$ & س & & \\
\hline $17 \ldots$ & 1.107 & $.1 \cdot 1$ & .r. & .7 .0 & $1 . \leqslant 0$. & 1977 & I.ro. & 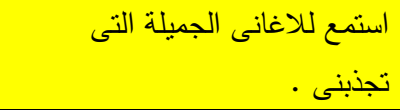 & 1 \\
\hline אחז.Tr & $r .1 \cdot 1$ & .178 & . &. .781 & $1 . \wedge 0$. & $.01 \mathrm{~T}$ & $1.0 \ldots$ & اثعر بايقاعات الموسيقى. & r \\
\hline YY.YYT & $r . \cdot \leq r$ & $.1 \leq V$ & •... & .781 & 1.70 &.$\leqslant \wedge \uparrow$ & 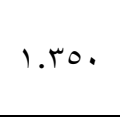 & 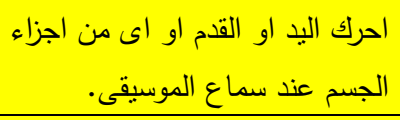 & $r$ \\
\hline $\mid V . r \leq 1$ & I.ANY & سזו. & .ro. & $\cdot \wedge \cdot 1$ & $1 . V \cdot$ & $\because . \leq \leqslant \leq$ & $1 . \leqslant 0$. & اعزف على اى من الالات & $\varepsilon$ \\
\hline r^.... & r.A. 9 & .1 ro & (. & $.0 . \mu$ & $1.7 \ldots$ & 1979 & 1. ro. & دوندن ببعض الاغانى التى افضلها & 0 \\
\hline tr.trt & $r . . \varepsilon r$ & $.1 \leq V$ & . & $\because v \leq 0$ & 1.70 & $\because \varepsilon \wedge 9$ & 1. 1. & 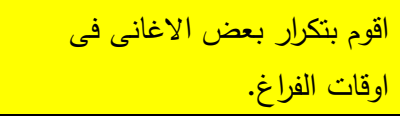 & 7 \\
\hline سז. & r.Trq & .104 & $\because \varepsilon \ldots$ & $.0 \cdot r$ & $1.7 \ldots$ &.$\varepsilon 1$ & I.r. & اذكر وانا اسمع الموسيقى . & V \\
\hline$r \varepsilon \ldots$ & $r . r \leq r$ & E & . . . . &.$\neg \wedge 7$ & 1.00. & דצח. & 1. ro. & لاخبز بين النبرات الصوتية من فرد & $\wedge$ \\
\hline rE.IT人 & r. $79 r$ & . . & . &.$\leqslant 1$ & $1 . \wedge \ldots$ &..$\leq \leq \leq \leq$ & $1 . \leqslant 0$. & 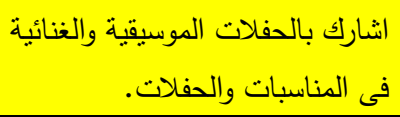 & 9 \\
\hline 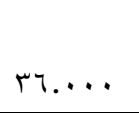 & r. r & $.1 \leq 0$ &.$\leq 0$. &..$\wedge \cdot 1$ & $1.8 \ldots$ & דצא. & 1. ro. & انقر بالاصابع على المنضدة بنغمة & 1. \\
\hline$r \leq . \leq r q$ & $0.1 \wedge r$ &..$T Y V$ & r.ro. & q r r. & 17.00. & r.rIr & . . . & المجموع & \\
\hline
\end{tabular}

قيمة ت الجدولية عند مستوى معنوية ه ... =

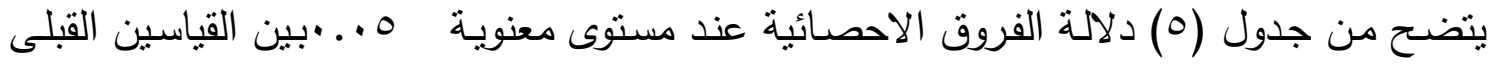

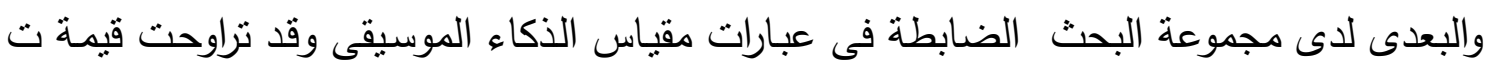

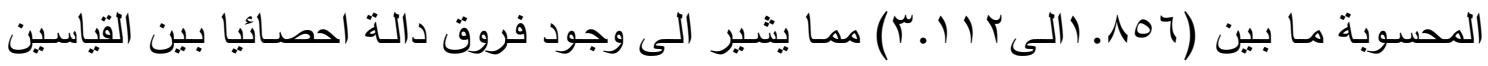

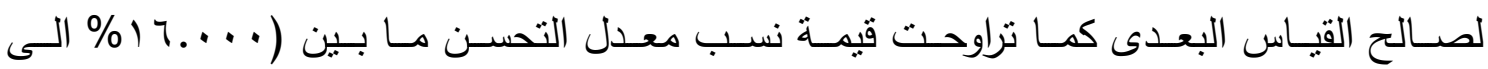




\section{جدول ( ) ( )}

دلالة الفروق بين القياسات البعدية لدى مجموعتى

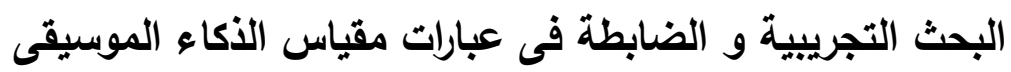

$r^{r}=r^{2}=1$ ن

\begin{tabular}{|c|c|c|c|c|c|c|c|c|}
\hline \multirow{2}{*}{ فروق نسب } & \multirow{2}{*}{ 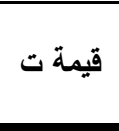 } & \multirow{2}{*}{ فروق } & \multicolumn{2}{|c|}{ المجموعة الضابطة } & \multicolumn{2}{|c|}{ المجموعة التجريبية } & \multirow[t]{2}{*}{ العبارات } & \multirow[t]{2}{*}{ م } \\
\hline & & & $\varepsilon \pm$ & س س & $\varepsilon \pm$ & س س & & \\
\hline 1.1 .491 & $0 . V \times 1$ & 1.0. & .7 .0 & $1 . \leqslant 0$. & $.01 T$ & r.o.. & تجذبنى • استمع للاغانى الجميلة التى & 1 \\
\hline TI.TYY & $\varepsilon . \wedge \vee \uparrow$ & $.9 \ldots$ & $\cdot .7 \times 1$ & 1.10 & $\because \varepsilon \varepsilon \varepsilon$ & r.vo. & اشعر بايقاعات الموسيقى. & $r$ \\
\hline 10.110 & $7 . r V \leq$ & 1.10. & $.7 \times 1$ & 1.70 & $\because \leqslant 1$ & r.A.. & الجرك البد او القدم او اى من اجزاء & $r$ \\
\hline$\Upsilon . \wedge \wedge \leq$ & 0.719 & 1.10. & $\cdot \wedge \cdot 1$ & $1.7 \ldots$ & זדצח. & Y.Ao. & المزف على اى من الالات & $\varepsilon$ \\
\hline 111.11. & $V . \varepsilon V r$ & 1.10 & $.0 . r$ & $1.7 \ldots$ & $\cdot . \leqslant \leq \leqslant$ & Y.Vo. & ادندن ببعض الاغانى التى افضلها & 0 \\
\hline ᄉ०. $\leqslant V$. & 0.190 & 1.0. & $\because V \leq 0$ & 1.70 & $\cdot \varepsilon V$. & $Y . V \ldots$ & $\begin{array}{r}\text { اقوم بتكرار بعض الاغانى فى الفراغ } \\
\text { اوقات }\end{array}$ & 7 \\
\hline $11 \varepsilon . \leqslant 9 \pi$ & A.VT. & $1 . r o$. & $\because 0 . r$ & 1.7. & • & r.Ao. & اذكر وانا اسمع الموسيقى & $V$ \\
\hline $110.1 \mathrm{H}$ & $7 . r 9 \wedge$ & $1 . r \ldots$ & $\cdot .714$ & 1.00 & $\cdot . \leqslant \leq \leqslant$ & r.vo. & لاخز & $\wedge$ \\
\hline 71.977 & $\vee .01$. & $1 \ldots$ & $\because \leqslant 1$ & $1 . \wedge \ldots$ & $\because \leqslant 1$. & r.A.. & 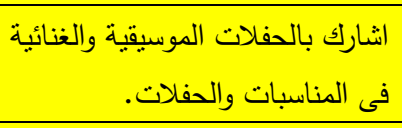 & 9 \\
\hline 11.491 & r.770 & $\because \wedge \ldots$ & $\cdot \wedge \cdot 1$ & $1.7 \ldots$ & .011 & r.o.. & 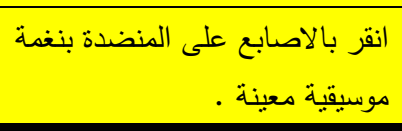 & 1. \\
\hline$\wedge \uparrow . \wedge \cdot \varepsilon$ & $1 \leqslant .909$ & $1 \cdot . v \cdot$ & r.1rq & 17.00 & r.rTA & TV.YO. & المجموع & \\
\hline
\end{tabular}

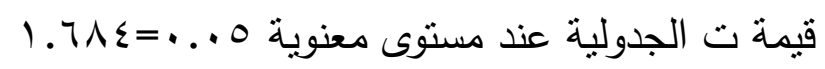

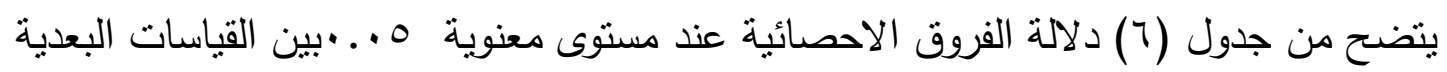

لاى مجموعتى البحث التجريبية والضابطة فى عبارات مقياس الذكاء الموسيقى وقد تراوحت قيمة ت

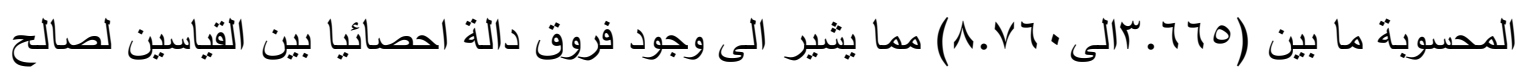

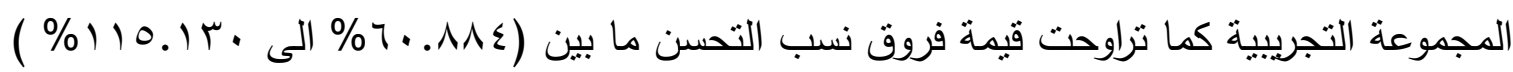


مناقشة نتائج الفرض الأول الذي ينص علي :

- توجد فروق دالة احصائية بين مستوى القياس القبلى والقياس البعدى لاقراد مجموعة البحث

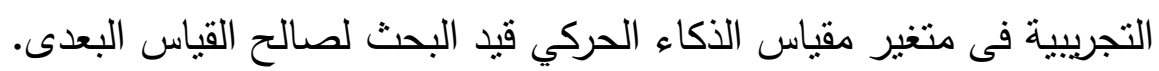

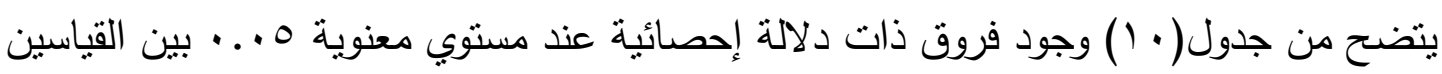

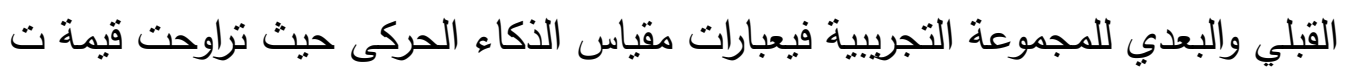

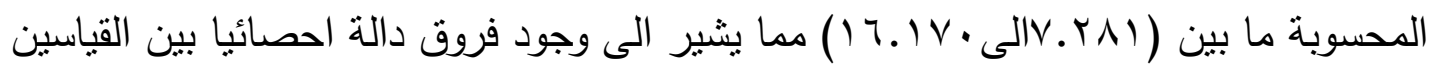

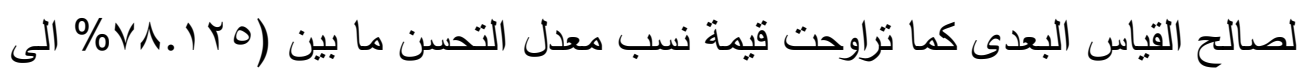
(\%) \&V.ArT

كما يتضح من جدول (1) أن قيم حجم التأثير لمقياس الذكاء الحركى لاى مجموعة البحث

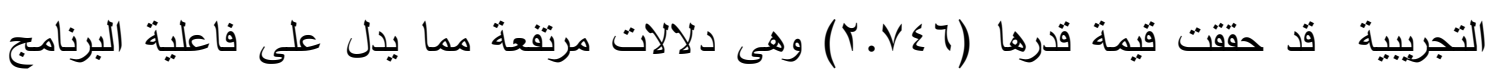
• بشكل قوى على المتغير التابع

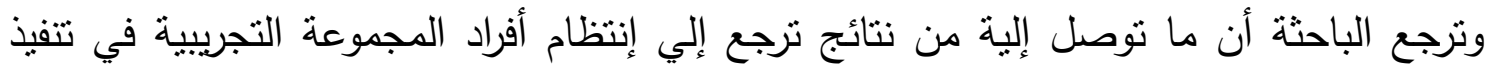

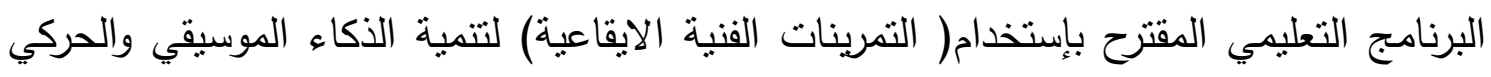

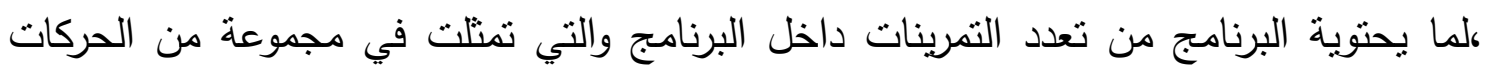

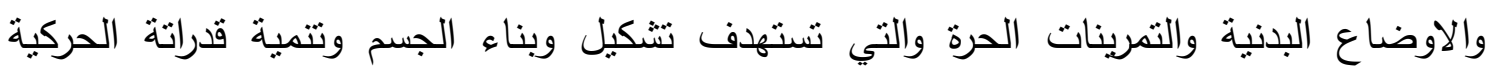
المختلفة للوصول للفردلاعلى مستوى من الاداء الرياضى والوظيفى وذللك من خلاد استخدام

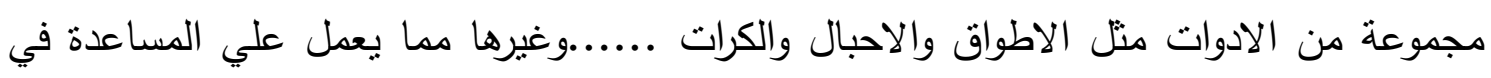
بناء اللياقة البدنية للجسم وزيادة قدرتة علي الحركة من خلال الجمل الحركية التي تتميز بالانسيابية والاستمرارية والمدي الكامل للحركة والاداء وبالتالي تتمية الذكاء الحركي قيد التيد البحث.

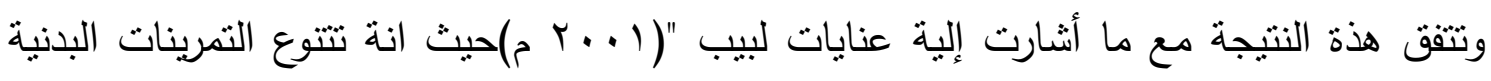

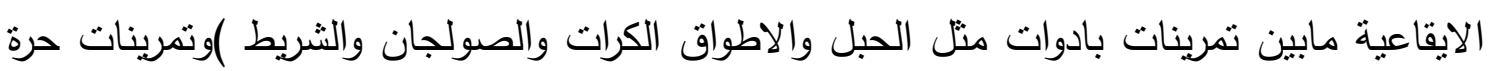

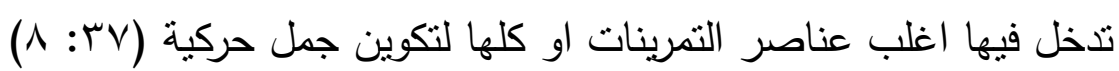

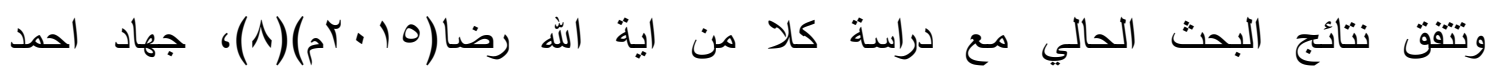

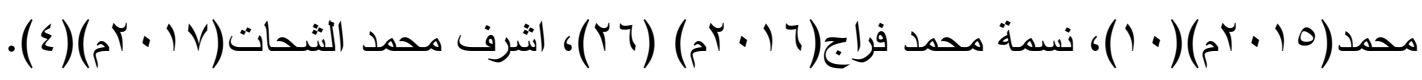
ومن خـلال عرض ومناقثـة وتقسير نتائج الفرض الأول ينضـح أنه قد تحقق إجرائيا من خـلال

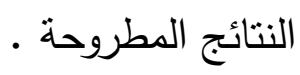




\section{مناقثنة نتائج الفرض الثاني الذي ينص علي:}

- توجد فروق دالة احصائية بين مستوى القياس القبلى والقياس البعدى لأفراد مجموعة البحث الضابطة فى متغير مقياس الذكاء الحركي قيد البحث لصالح القياس البعدى.

ويتضح من جدول(Y I ) وجود فروق ذات دلالة إحصائية عند مستوي معنوية ه .. . بين القياسين

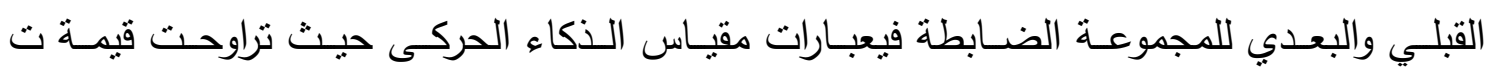

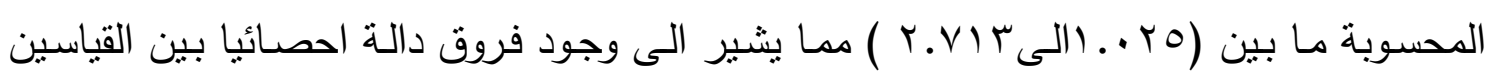

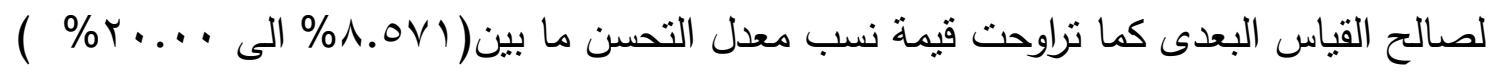

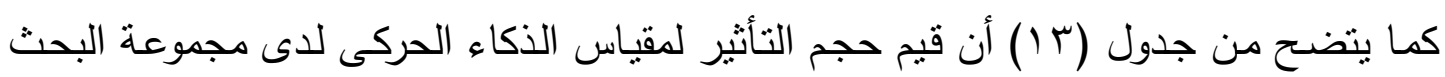

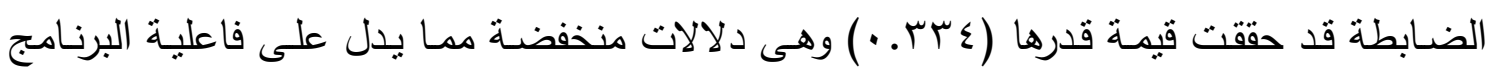
• التقليدي بشكل ضعيف وترجع الباحثة أن ما توصل إلية من نتائج ترجع إلي ان أفراد المجموعة كانو يستخدومون الاسلوب

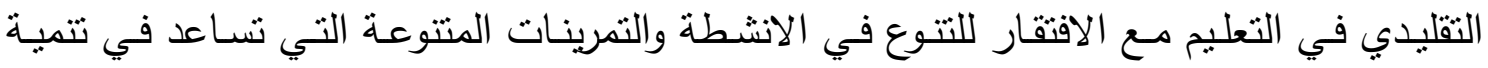
الذكاء الحركي للطلاب وذلك من خـال استخدام اسلوب واحد في التعليم وهو الاسلوب التقليدي

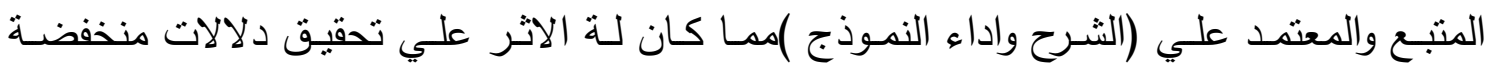
وتاثيرات غير فعالة بالثكل المطلوب علي الذكاء الحركي قيد البحث .

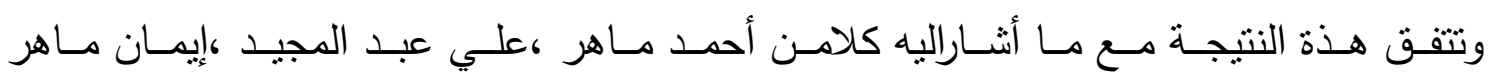

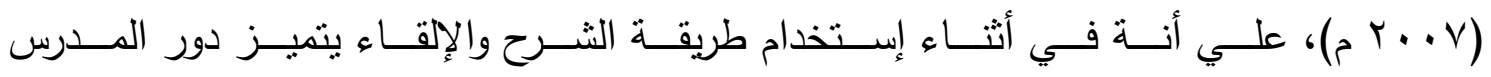
بالإيجابيـة والتلميذ دائمـا مـا يكون منلقي للمعلومـات وتتبـع هذة الطريقـة عدة أنشكال يمكن أن يتبعها المدرس تتمثل في:

أ. التحاضر : ويعرض المدرس الحقائق دون إثنراك الطلاب ولاتقدم أب أسئلة إلابعد إنتهاء

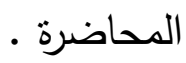
ب. الثرح : ومهمتة إظهار أساسيات الموضوع والتنرج من معلومة إلي أخري. ج. الوصف : وهي وسيلة للإيضاح اللفظي في حالة عدم توفير الوسلئل الحسيـة. 
د. القصص : وهي من الأشياء التي يميل إليها الصغار والكبار وهي تشاعد علي جذب إنتباة

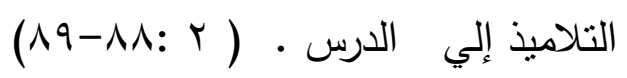

وتتفق هذه النتائج السابقة مع دراسات كلامن سلوي محمد درويش (r ( • r م)( ( )، اية الله رضا

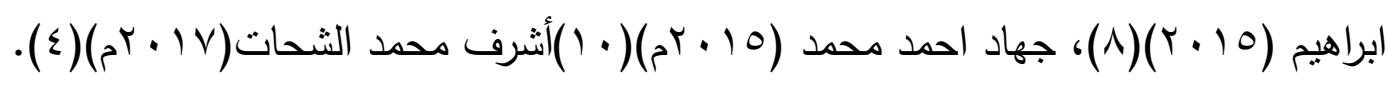

ومن خـلال عرض ومناقثــة وتفسير نتائج الفرض الثاني يتضـح أنسه قد تحقق إجرائيا من خـلال

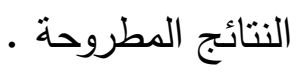

\section{مناقشة نتائج الفرض الثالث الأي ينص علي:}

- توجد فروق دالة احصائية بين مستوى القياس البعدى لكل من المجموعة التجربيية والضابطة في منغير الذكاء الحركي لصالح القياس البعدي للمجموعة التجريبية.

يتضح من جدول(ع ( ) وجود فروق ذات دلالة إحصائية عند مستوي معنوية ه ـ. •بين القياسات البعدية لدى مجموعتى البحث التجريبية والضابطة فى عبارات مقياس الذكاء الحركى حيث

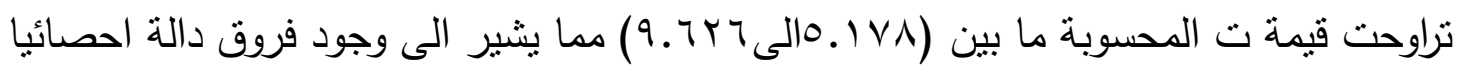
بين القياسين لصالح المجموعة التجريبية كما تراوحت قيمة فروق نسب التحسن ما بين

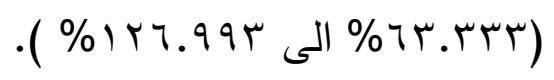

كما يتضح من جدول (0) (10) ان قيم حجم التاثير لمقياس الذكاء الحركى بين مجموعتى

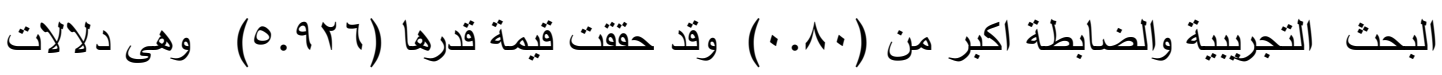
مرتفعة •مما يدل على فاعلية البرنامج . . . . بشكل مرتفع على تللك المتغيرات لصالح المجموعة التجربيية عنة لدى المجموعة الضابطة. وترجع الباحثه ذلك التحسن في متغير الذكاء الحركي قيد البحث لصالح أفراد المجموعة التجريبية مقارنـة بالمجموعة الضـابطة إلي فاعلية البرنـامج التعليمي المقترح التمرينات الفنية الايقاعية لمـا يحتويـة البرنـامج مـن تعـد التمرينـات داخلـل البرنـامج والتـي تمثلت في مجموعـة مـن الحركـات والاوضـاع البدنيـة والتمرينـات الحـرة والتي تسـتهدف تشـكيل وبنـاء الجسـم وتتميـة قدراتـة الحركيـة المختلفة للوصول للفردلاعلى مستوى من الاداء الرياضـى والوظيفى وكذللك من خلال التتوع في

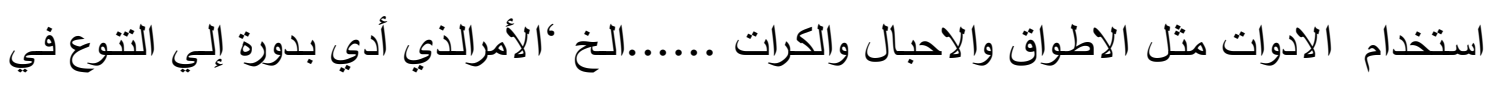
الانشطة التي سـاعدت علي تتميـة انشطة الذكاء الحركي والابتكـار لدي الطـلاب وتوفير بيئة تعليمية تتاسب معظم أفراد المجموعة التجريبية مدا كان لة الأثر في إستتارة دوافع الطلاب وزيادة 
مشاركتهم الفعالة في البرنامج المقترح ،وهذا يختلف بدورة عن الأسلوب النقليدي (الثرح والإلقاء )

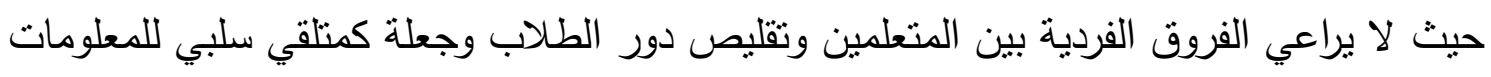

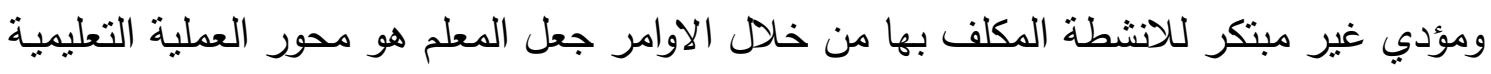

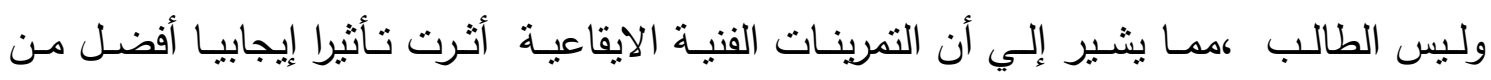

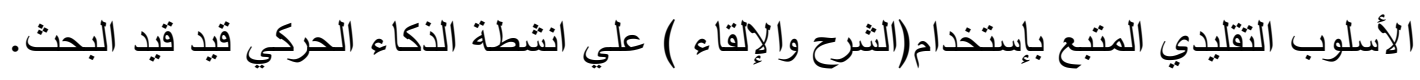

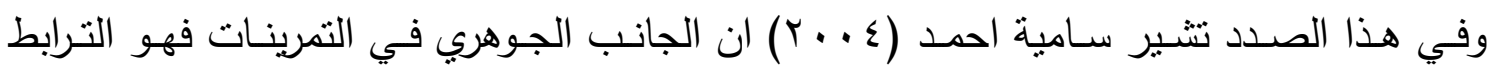

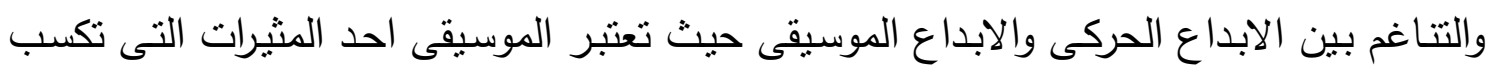

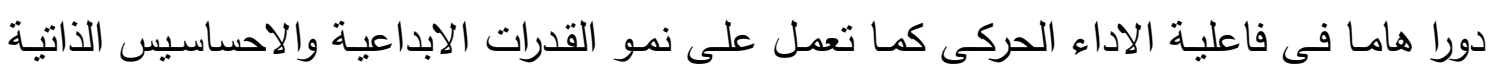

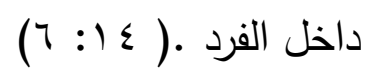
وتعزو الباحثة التحسن في الذكاء الحركي لافراد المجموعة التجريبية عنة في المجموعة الضابطة

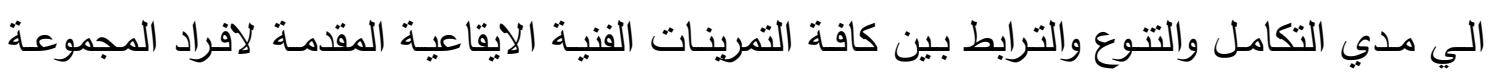

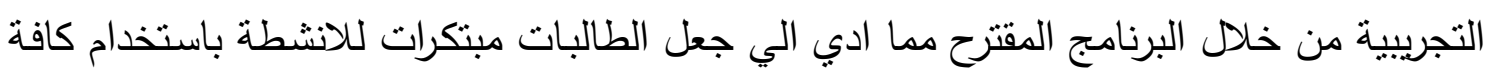

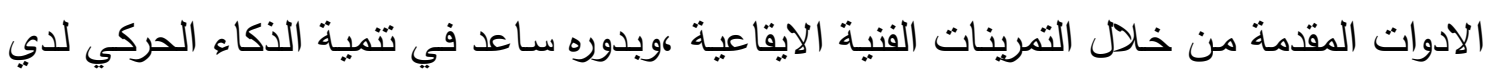

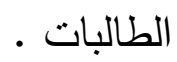
ويتقق ذلك مع نتائج دراسات كلا من ،سلوي محمد درويش(r ( • rم)(T (1)، اية اله رضا ابراهيم

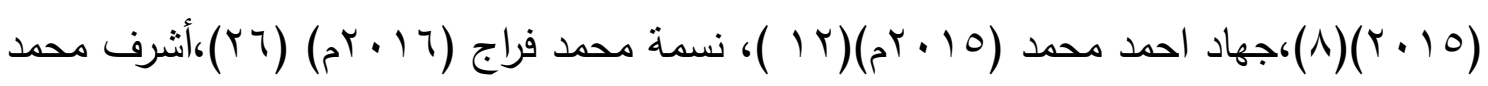

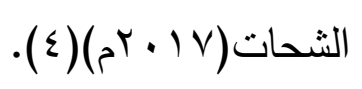

ومن خـال عرض ومناقثـة وتفسير نتائج الفرض الثالث يتضـح أنه قد تحقق إجرائيا من خـلال النتائج المطروحة .

\section{مناقثة نتائج الفرض الرابع الذي ينص علي :}

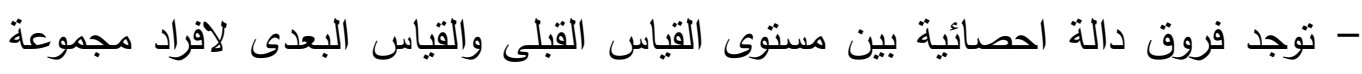
البحث التجريبية فى متغير مقياس الذكاء الوسيقي قيد البحث لصالح القياس البعدى.

يتضح من جدول(7 ( ) وجود فروق ذات دلالة إحصائية عند مستوي معنوية ه . . بين القياسين

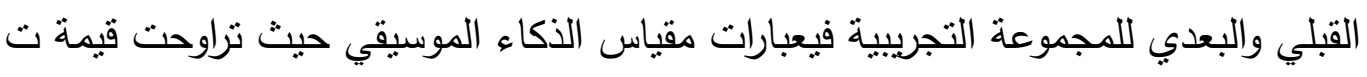

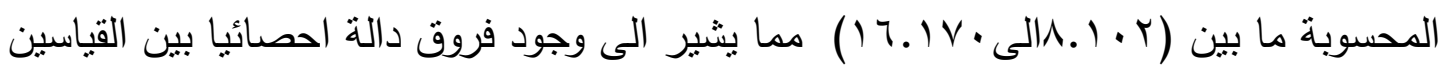




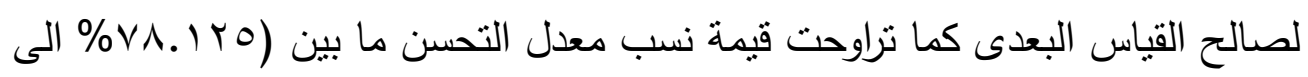
(\%) $\leqslant \vee . \wedge r T$

كما يتضح من جدول (V) أن قيم حجم التأثير لمقياس الذكاء الحركى لاى مجموعة البحث

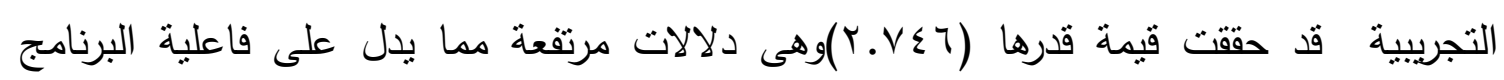
بشكل قوى على المتغير التابع • وترجع الباحثة أن ما توصل إلية من نتائج ترجع إلي إنتظام أفراد المجموعة التجريبية في تتفيذ

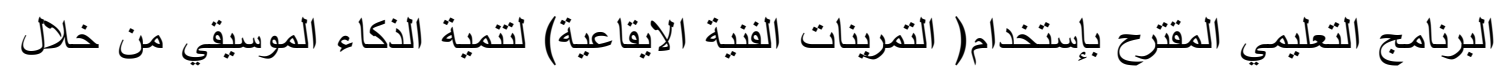

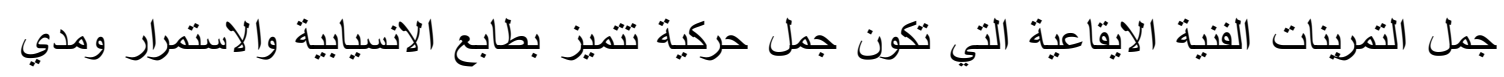

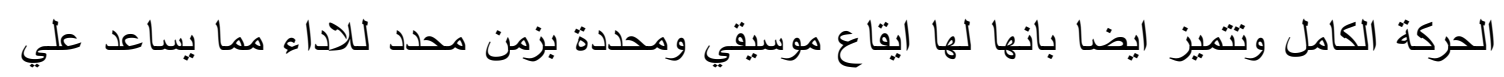
تتمبة الرنم الموسيقي والتوافقي للحركة من خلال تتمية الكاء الموسيقي وضبط ايقاعات الحركة

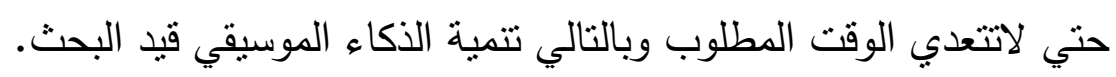

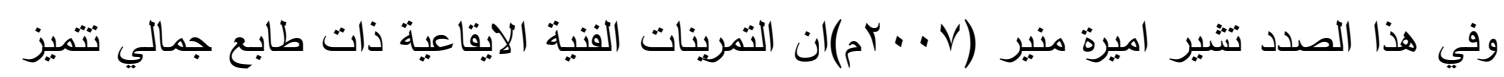

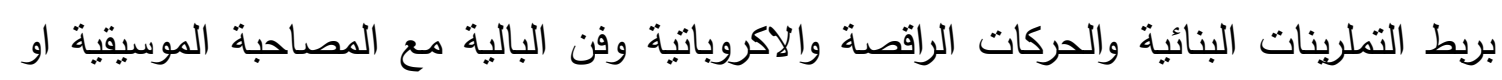
الرتم الموسيقي (1: 7 )

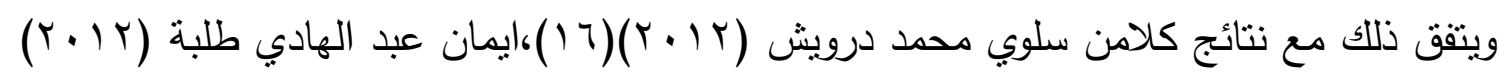

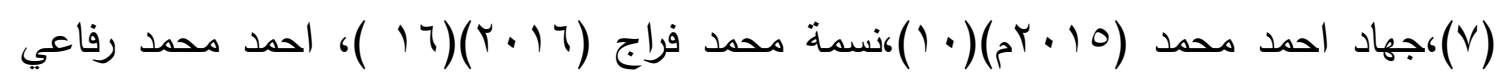
$\cdot(r)(5 r+1 V)$

ومن خـلال عرض ومناقتنة وتفسير نتائج الفرض الرابع يتضـح أنه قد تحقق إجرائيا من خـلال

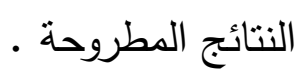

\section{مناقثة نتائج الفرض الخامس الأي ينص علي :}

- توجد فروق دالة احصائية بين مستوى القياس القبلى والقياس البعدى لافقراد مجموعة البحث

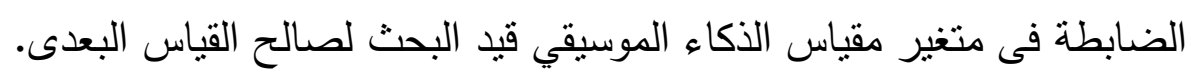

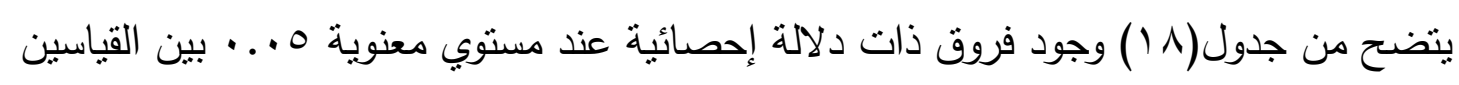

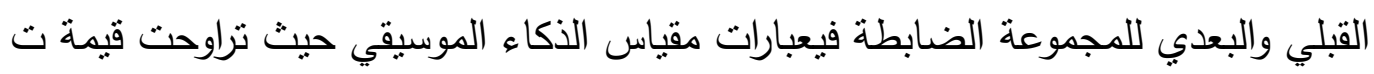

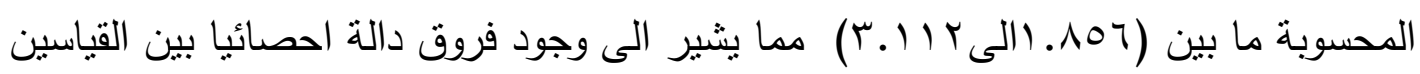

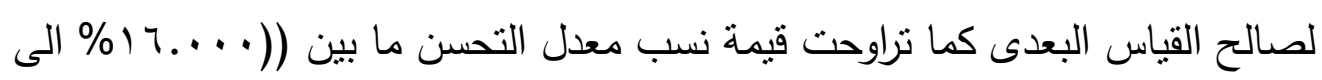
( ) \% \% 
كما يتضـح من جدول (9 (1) أن قيم حجم التأثير لمقياس الذكاء الموسيقي لدى مجموعة البحث

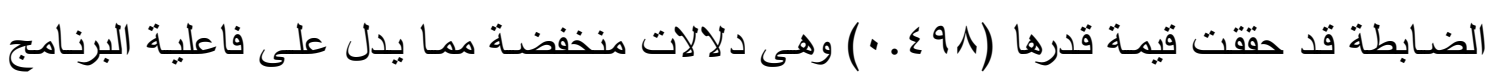
التقليدي بشكل ضعيف علي المتغير التابع ( الذكاء الموسيقي).

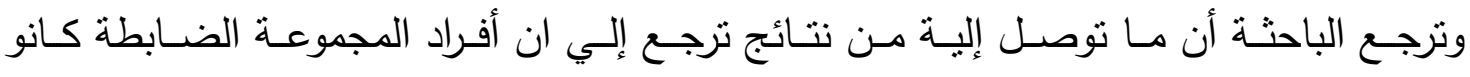

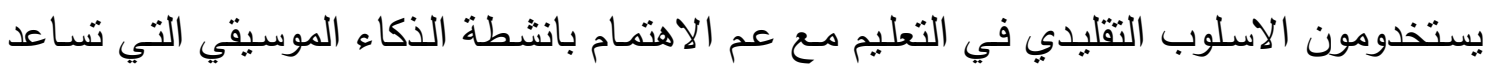

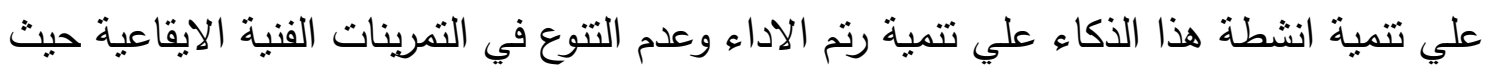

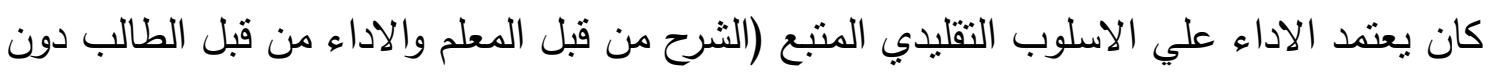

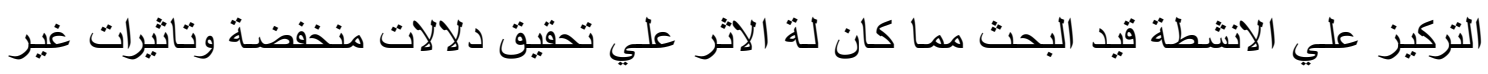

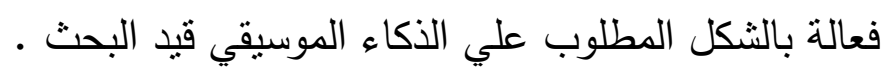

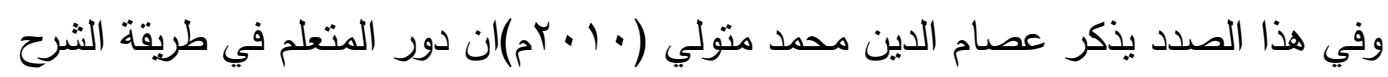

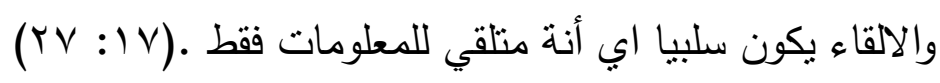

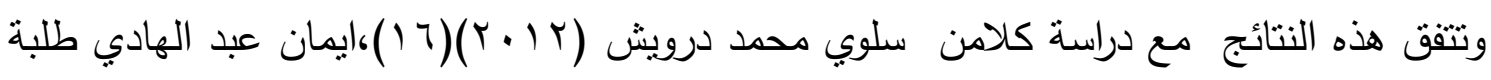

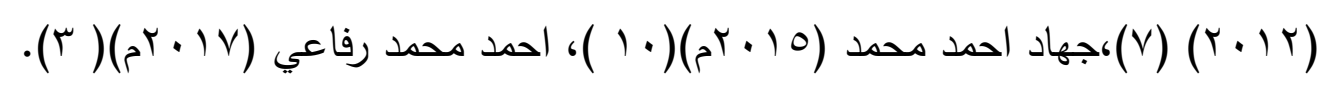

ومن خلال عرض ومناقثة وتفسير نتائج الفرض الخامس بتضح أنه قد تحقق إجرائيا من خلال

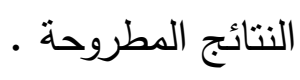

\section{مناقثة نتائج الفرض السادس الذي ينص علي:}

- توجد فروق دالة احصائية بين مستوى القياس البعدى لكل من المجموعة التجريبية والضابطة في متغير الذكاء الموسيقي لصالح القياس البعدي للمجموعة التجريبية.

يتضح من جدول(· (Y) وجود فروق ذات دلالة إحصائية عند مستوي معنوية ه .. ببين القياسات

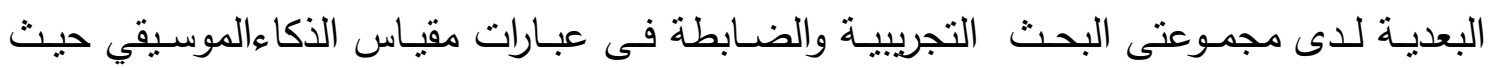

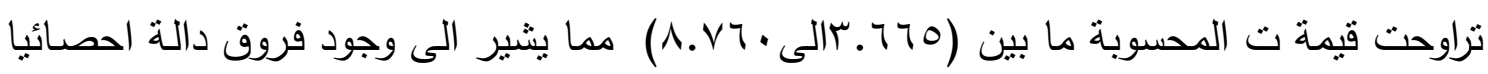

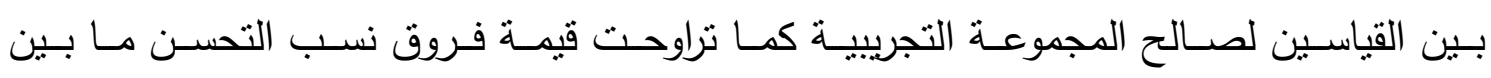

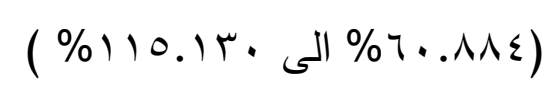

كما يتضـح من جدول (Y) ان قيم حجم التاثير لمقياس الذكاء الموسيقي بين مجموعتى البحث

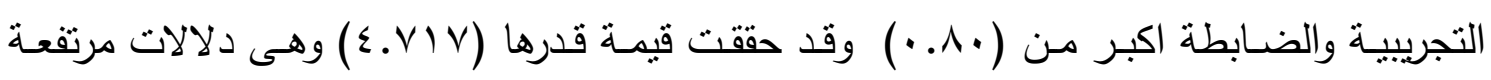


•مما يدل على فاعلية البرنامج التعليمي المقترح باستخدام التمرينات الفنية الايقاعية بشكل مرتفع على تلك المتغيرات لصالح المجموعة التجريبية عنة لدى المجموعة الضابطة.

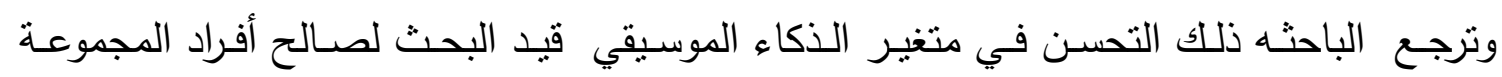

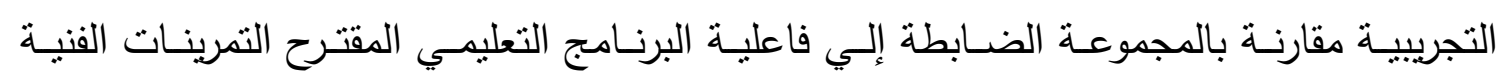

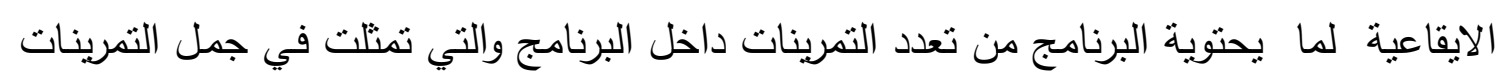

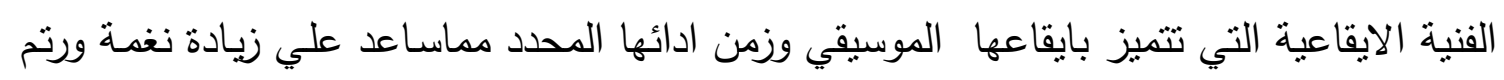

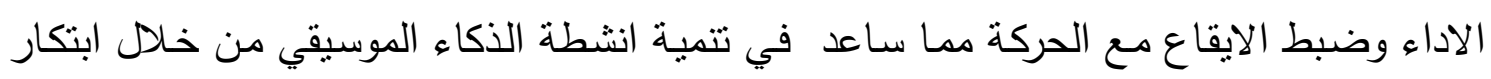

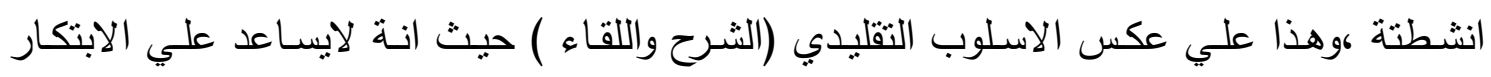

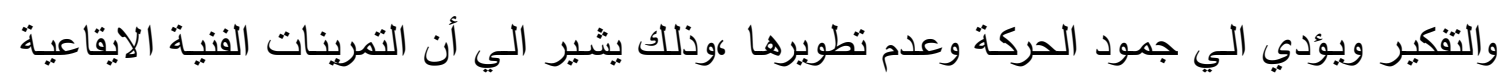

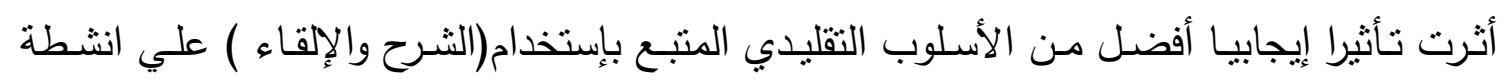
الذكاء الموسيقي قبد البحث.

وفي هذا الصدد يشير محمد عبد الهادي (r . . rم)الي ان الذكاء الموسيقي يتمثل في القدرة علي

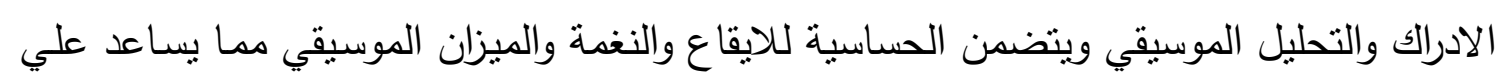

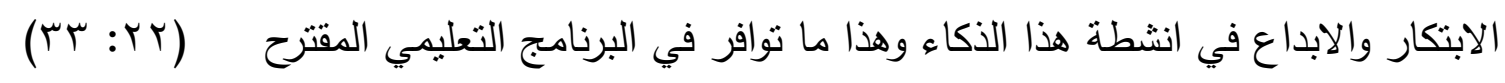
وتعزو الباحثة التحسن في الذكاء الموسيقي لافراد المجموعة التجريبية عنة في المجموعة الضـابطة التهاء

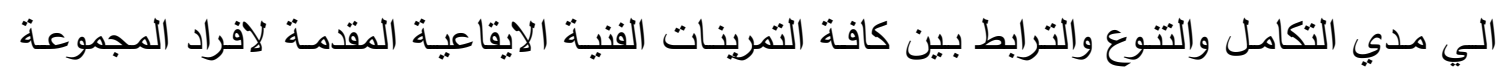
التجريبية من خلال البرنامج المقترح مما ادي الي جعل الطالبات مبتكرات للاننشطة من خـلال

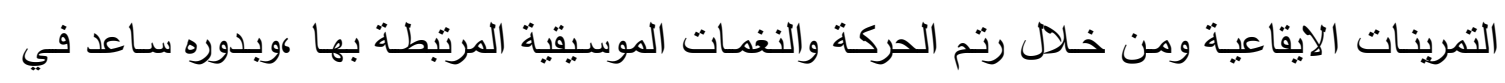
تتمية أنشطة الذكاء الموسيقي لاي الطالبات .

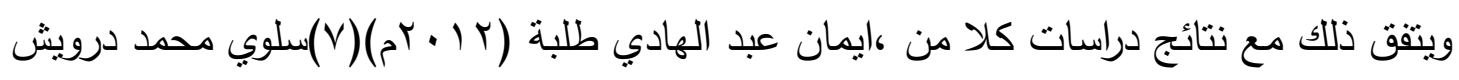

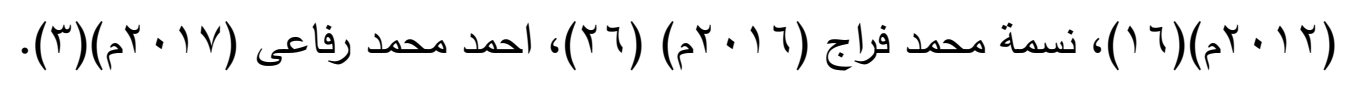

ومن خلال عرض ومناقثة وتفسبر نتائج الفرض السادس يتضح أنه قد تحقق إجرائيا من خلال

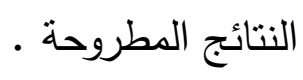
الاستنتاجات:-

في حدود هدف البحث وفروضـه، وفي ضوء النتائج التي توصلت اليها الباحثة، وبعد تحليلها احصائيا، ومناقثتها وتفسيرها قد توصلت الباحثة للاستتناجات الاتية : 
ا. برنامج التمرينات الفنية الايقاعية له تأثير ايجابي علي تتمية مهارات الذكاءالموسبقى والذكاء

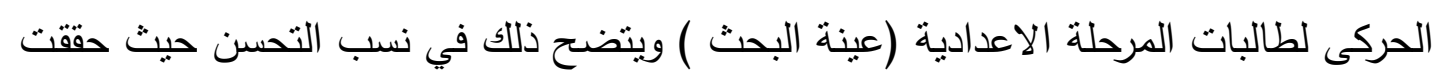

$$
\text { القيم دلالات مرتفعة }
$$

r. التمرينات الفنية الايقاعية لها ناثير لها تأثير ايجابي ودور فعال في تتمية ذكاءات الطالبات.

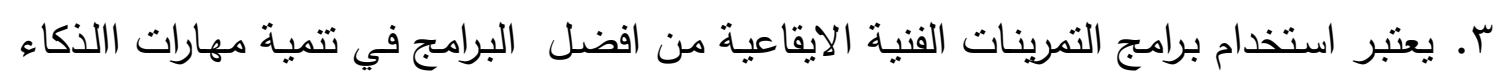
وبالاخص الذكاء والذكاء الحركى موضوع البحث للطالبات. التوصيات:-

استتادا إلى النتائج التي توصلت إليها الباحثة من خلال إجراء هذا البحث توصى الباحثة بالآتي:

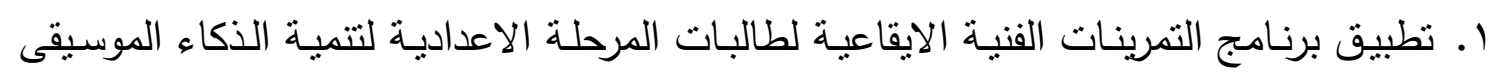

$$
\text { والحركى للطالبات. }
$$

r. ان تواكب برامج التربية والتعليم حاجات وميول الطالبات علي جميع المسنويات.

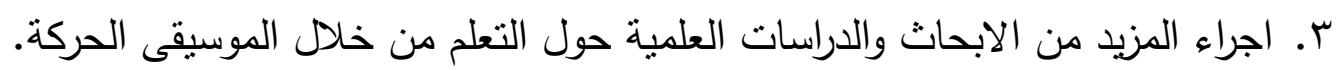

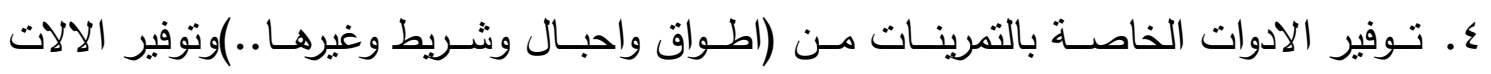
الموسيقية الخاصة بمصاحبة النشاط والتي تتلائم مع طبيعة هذه المرحلة .

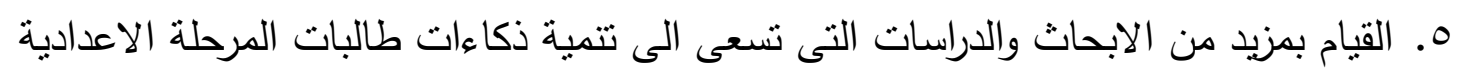

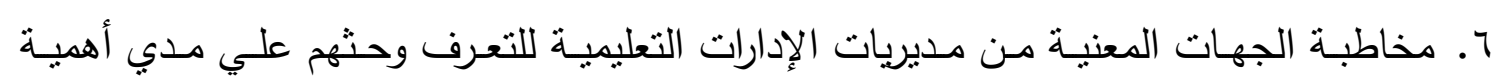

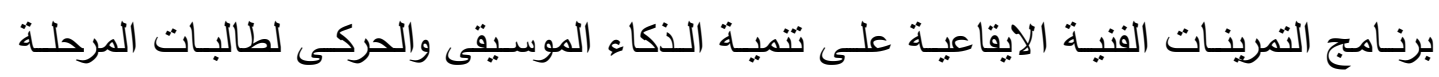
الاعدادية V. تعديل منهج التمرينات الفنية الايقاعية للمرحلة الاعدادية بما يناسب احتباجات الطالبات فى لئ هذة المرحلة .

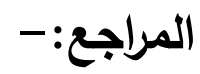

اولا : قائمة المراجع باللغة العربية

1- احمد السعيد عبدالفتاح الجلمة(1) ـ r ):-"تاثير استخدام التعليم المتميز على تحصيل مقرر طرق التدريس لطلبة افرقة الثانية بكلية التربية الرياضية - جامعة كفر الثيخ ،رسالة

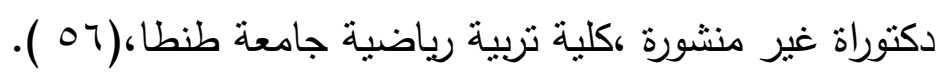




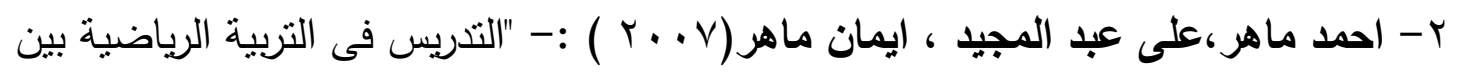

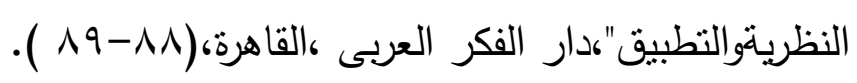

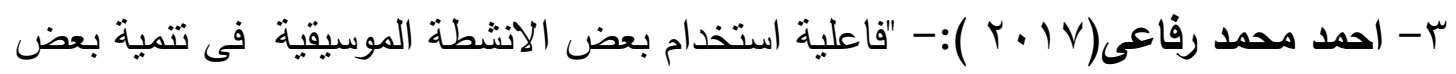
المهارات الموسيقية فى ضوء تلاميذ مرحلة التعليم الاساسى"، رسالة ماجستيرغبر منشورة

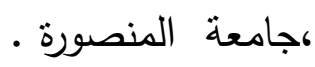

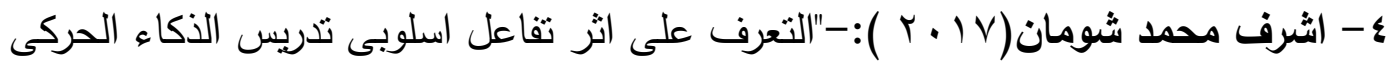

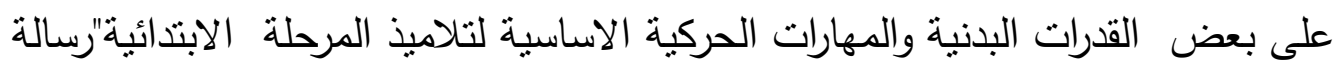
دكتوراة غير منشورة،جامعة الاسكندرية .

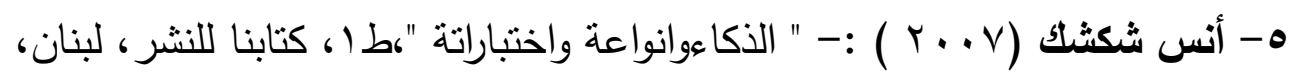
المنصورية(9 ع ).

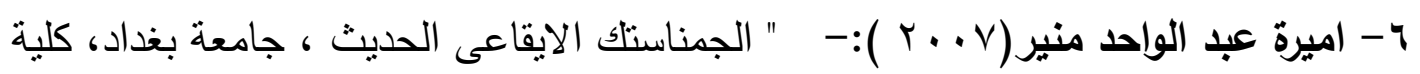
التربية الرياضية،كانون الثانى ،الاكاديمية الرياضية العراقية الاليكترونية ،العراق،( ( ).

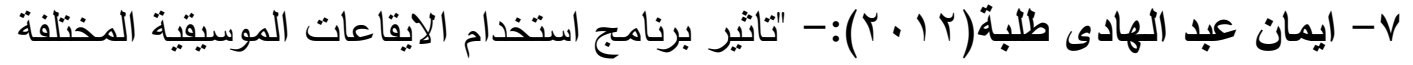
على تعلم بعض المهارات الاساسية فى التمرينات الفنية الايقاعية ،رسالة دكتوراة غير

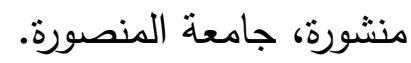

1- ايه الله رضا ابراهيم (10 • ب ):- "بناء مقياس للذكاءالحركى وعلاقتة بمستوى الانجاز لطلاب كلية تربية رياضية - جامعة الثيخ"،رسالة ماجستيرغير منشورة، جامعة كفر الثيخ • لهاهي

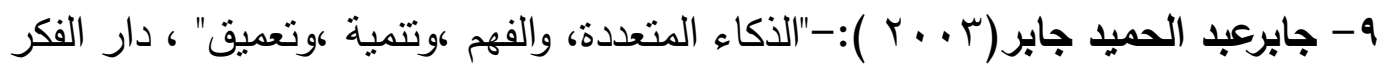

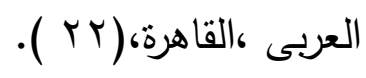

• 1 - جهاد احمد محمد(10 r ) :- "تاثير برنامج تمرينات للادراك الحسى الحركى باستخدام الوسائط القائمة على مستوى اداء بعض مهارات التمرينات الفنية الايقاعية لطالبات نربية رياضية جامعة المنيا"، رسالة ماجستير غير منشورة ، جامعة المنيا. 


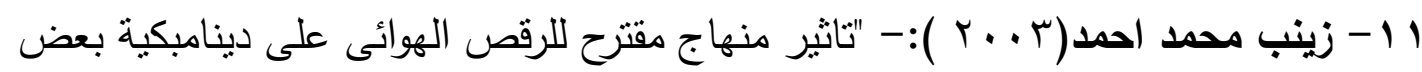
المتغيرات الفسيولوجية والجسمية"، رسالة ماجستير غير منشورة،كليةالتنبية الرياضية للبنات

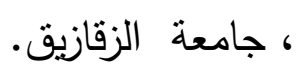

r ا - زين العابدين وهبة( ( . † ):- " تتبؤ الذكاءات المتعددة بالدافعية الذاتية"، ط ا، دار

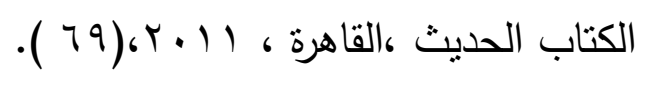

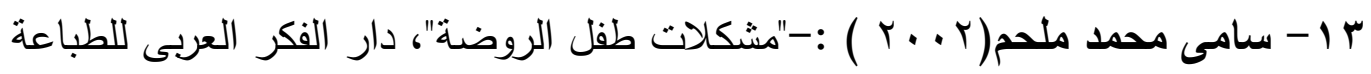
والنشروالتوزيع ، القاهرة ، (ه ).

צ ا - سامية كامل الهجرسى(9 . . ץ ):- "التمرينات الايقاعية والجمباز الايقاعى .المفاهيم العلمية والفنية"،مكتبة ومطبعة الغد،القاهرة ،(7).

ه - سعاد احمد الزبانى(r r ـ r ):- "الاعداد الموسيقى لمعلمة الحضانة ورياض الاطفال"، دار الفكرالعربى ، القاهرة ،(0) )

47 - سلوى محمد درويش(r ( • r ):- "استخدام الذكاء الموسيقى والذكاء الحركى الجسىى فى تدريس اللغة الانجليزية للمرحلة الابتدائي ،رسالة ماجستير غير منشورة،جامعة عين شمس.

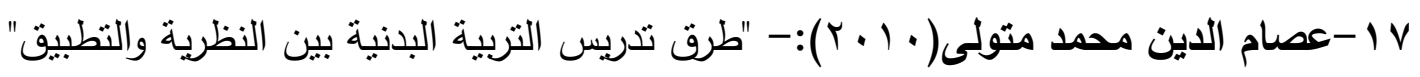
،دار الوفاء لدنيا الطباعة والنشر ،الاسكندرية،(؟ ) ).

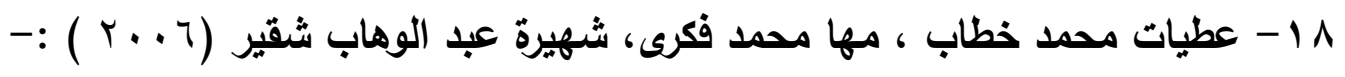
" اساسيات التمرينات والتمرينات الايقاعية"،مركز الكتاب للنشر، القاهرة، (ب م ).

9 1 - عنايات لبيب،بركسان عثمان( ( . ـ ) )- "التمرينات الايقاعية والجمباز الايقاعى" ،دار

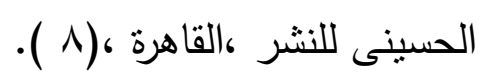


• ץ - فتحى احمد ابراهيم اسماعيل(^ . . ץ ):- " المبادىء والاسس العلمية للتمرينات البدنية والعروض الرياضية" ،دار الوفاء لدنيا الطباعة والنشر ،الاسكندرية، (r ).

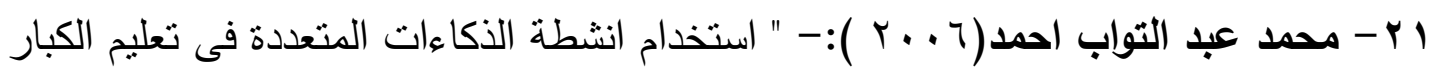
واثرها فى دافعيتهم واتجاههم نحو التعليم،دراسة ماجستيرغير منشورة فى التربية، قسم علم التفس التعليمى ، كلية التربية ، جامعة اسيوط .

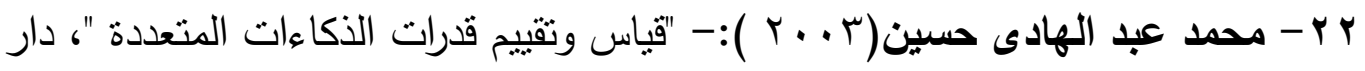

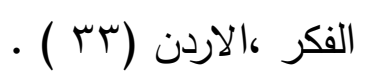

ץ ץ-منال محمد ذكى الجندى(ך . ץ):- "تدريس منهج الايقاع الحركى المطور بالاستراتيجيات

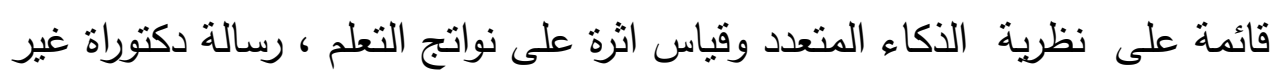
منشورة ، كلية التربية الرياضية للبنات ، جامعة الاسكندرية (0ء ) ).

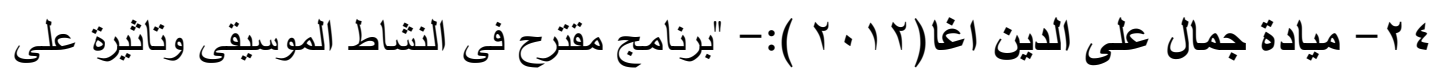
تتمية كل من الذكاء الحسى الموسيقى لدى اطفال المرحلة ماقبل المدرسة"، رسالة دكتوارة غير منشورة ،كلية تربية نوعية ، جامعة الاسكندرية ، (0؛ ) .

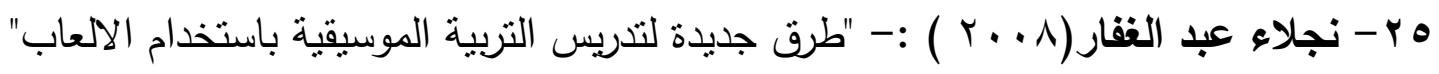
دار العلم والايمان للنشر والتوزيع،كفر الثيخ،(به مائه ) -

צ r - نسمة محمد فراج(7 1 • r ):-"تاثير برنامج تمرينات المقاومة الكلية للجسم على مستوى اداء بعض المهارات الاساسية فى التمرينات الفنية الايقاعيةوالصفات البدنية لطالبات كلية التربية الرياضية بنات"، رسالة ، دكتوراة غير منشور ،جامعة المنصورة .

ثانبا : قائمة المراجع باللغة الاجنية

Y $\vee$ - Gardner, Howarde. Intelligence reframed: Multiple intelligences for the 21st century. Hachette UK, 2000 